\title{
Physical modeling of Polymer-Electrolyte Membrane Fuel Cells: Understanding water management and impedance spectra.
}

\author{
Georg A. Futter ${ }^{\mathrm{a}}$, Pawel Gazdzicki ${ }^{\mathrm{a}}$, K. Andreas Friedrich ${ }^{\mathrm{a}}$, Arnulf Latz ${ }^{\mathrm{a}, \mathrm{b}}$, \\ Thomas Jahnke ${ }^{\mathrm{a}, *}$ \\ ${ }^{a}$ German Aerospace Center (DLR), Institute of Engineering Thermodynamics, \\ Pfaffenwaldring 38-40, 70569 Stuttgart, Germany \\ ${ }^{b}$ Helmholtz Institute Ulm for Electrochemical Energy Storage (HIU), Helmholtzstraße 11, \\ 89081 Ulm, Germany
}

\begin{abstract}
A transient 2D physical continuum-level model for analyzing polymer electrolyte membrane fuel cell (PEMFC) performance is developed and implemented into the new numerical framework NEOPARD-X. The model incorporates nonisothermal, compositional multiphase flow in both electrodes coupled to transport of water, protons and dissolved gaseous species in the polymer electrolyte membrane (PEM). Ionic and electrical charge transport is considered and a detailed model for the oxygen reduction reaction (ORR) combined with models for platinum oxide formation and oxygen transport in the ionomer thin-films of the catalyst layers (CLs) is applied. The model is validated by performance curves and impedance spectroscopic experiments, performed under various operating conditions, with a single set of parameters and used to study water management in co- and counter-flow operation. Based on electrochemical impedance spectra (EIS) simulations, the physical processes which govern the PEMFC performance are analyzed in detail. It is concluded that the contribution of diffusion through the porous electrodes to the overall cell impedance is minor, but concentration gradients along the channel have a strong impact. Inductive phenomena at low
\end{abstract}

\footnotetext{
${ }^{*}$ Corresponding author. German Aerospace Center (DLR), Institute of Engineering Thermodynamics, Computational Electrochemistry, Pfaffenwaldring 38-40, 70569 Stuttgart, Germany

Email address: thomas.jahnke@dlr.de (Thomas Jahnke)
}

Preprint submitted to Journal of Power Sources

December 10, 2018 
frequencies are identified from physics-based modeling. Induction is caused by humidity dependent ionomer properties and platinum oxide formation on the catalyst surface.

Keywords: Polymer electrolyte membrane fuel cell, Physical modeling, Multiphase flow, Electrochemical impedance spectroscopy, Impedance analysis, Inductive phenomena

\section{Introduction}

Polymer electrolyte membrane fuel cells are promising systems for energyconversion in particular for automotive applications. Over the last decades, the cell performance and durability has been improved significantly. However, durability remains still an issue. Thus, multi-scale modeling of PEMFC performance and degradation phenomena is a field of active research [1] with the aim to enable the technological breakthrough. Continuum-level modeling has helped to identify the physical processes which govern the cell performance. Still, improved models for the description of multiphase flow, catalyst layers and the ionomer properties are needed [2].

For the macroscopic description of the PEM, physical models for the sorption isotherm, determining the equilibrium water content in the membrane as a function of water activity, are applied. The existence of Schroeder's paradox for the membrane [3], i.e. increased water uptake of a liquid-equilibrated membrane compared to a vapor-equilibrated state, is under debate [1]. A possible explanation for the phenomenon is the existence of an 'extended surface layer' [4] which rapidly restructures upon contact with liquid water. However, physical models describing the process are missing. Based on the equilibrium state, the kinetics of water uptake are modeled using mass transfer coefficients which may depend on the temperature, humidity and the mechanical properties of the membrane $[5,6,7,8,9]$. The models for water transport inside the membrane take into account diffusive transport [10], convection [11, 12, 13], or transport due to gradients of the chemical potential $[14,15,16]$. 
The most complex layers of the PEMFC are the catalyst layers (CLs). The electrochemical half-cell reactions are mostly described using Butler-Volmer (BV) equations. For the ORR, a doubling of the Tafel slope has been observed $[17,18,19,20]$ which has been taken into account by the use of different transfer coefficients, depending on the cell voltage [21, 22]. Alternatively, for the ORR, elementary kinetic 'double-trap' models are applied [23, 24, 25, 26]. Due to the confined pore space in this layer, Knudsen diffusion has to be considered in the gas phase [2]. In addition to the flow of liquid water, oxygen transport resistances in the ionomer need to be considered [27, 28, 29]. Agglomerate models $[30,21,31,32,33,22]$ have aimed to describe these resistances using efficiency factors in combination with BV equations and the Thiele modulus. In some models, the effective agglomerate surface has been assumed to be two orders of magnitude lower than the electrochemically active surface area (ECSA) and extremely large agglomerate radii were employed to fit experimental data. This indicates that a relevant resistance has been missing in these models. Further, in [34], it was concluded that in state-of-the-art CLs, with agglomerate radii smaller than $100 \mathrm{~nm}$, agglomerate effects manifest themselves only below $0.1 \mathrm{~V}$ and are therefore negligible. Consequently, novel ionomer film models, which describe the oxygen transport resistance in ionomer thin-films have been developed [35].

For the rigorous simulation of gas and liquid transport in the gas diffusion layer (GDL), a multiphase Darcy approach has been applied [36, 37, 38, 39], which requires correlations for the relative permeability and capillary-pressuresaturation-relation. Alternatively, the multiphase mixture model [40] has been used in order to speed up the computations. However, the interfaces between single and two-phase regions are not tracked rigorously and no net benefit is seen for PEMFC modeling using this approach [2].

To obtain a reliable cell-level model of a PEMFC, the best models for the description of ionomer properties, electrochemistry and transport need to be united. The combined model should be able to describe all experimental observations and still be as simple as possible. In this work, we aim to develop such 
a model, by relaxing many crucial assumptions made in recent PEMFC models.

As discussed above, many PEMFC models do not treat two-phase flow rigorously. Instead, liquid water is often assumed to exist as droplets in the gas phase [10]. In this case, the gas phase is supersaturated and the water activity is allowed to exceed unity. In this work's formulation, two-phase flow is treated rigorously.

For the ORR, most often overly simplified BV equations are employed which are not able to capture the reaction kinetics in different voltage regimes. Further, the spatial resolution of the CLs is often neglected. However, as will be shown in this study, this assumption needs to be relaxed in order to obtain realistic results. To describe mass transport losses, the oxygen transport resistances in the ionomer thin-films, covering the carbon and platinum in the CLs, need to be taken into account. All important aspects of the electrode models, governing the cell performance, are combined in this work.

Finally, the model needs to be validated with dedicated experiments. A valid model will be able to describe all observations with a single set of realistic parameters. Many PEMFC models published today are poorly validated. In this study, the importance of validation under a broad range of operating conditions is emphasized. In addition to polarization curves, EIS should be used for model validation. Therefore, a transient model is developed in this work.

The paper is organized as follows. The model description, the numerical framework and the experiments are presented in Sections 2 to 4, respectively. The results are discussed in Section 5. The model validation, presented in Fig. 2 is the basis for the subsequent results. It is essential for significant model predictions under conditions that have not been measured and supports simulation results that are experimentally not accessible. After the model validation, we allow ourselves to present simulation results which are not comparable with experiments. With the results depicted in Fig. 3, we start to rationalize the validation results and highlight the importance of the spatial resolution of the CLs in PEMFC modeling. With Fig. 4 we dive deeply into the analysis of PEMFC water management and illustrate how internal humidification [41] proceeds, es- 
pecially in counter flow mode. The rigorous treatment of multi-phase flow is demonstrated in Fig. 5. All this paves the way for the impedance analysis, the central findings of the paper, which are presented in Fig. 6 and Fig. 7.

\section{Mathematical model}

The mathematical model is based on the following assumptions:

1. Each layer of the membrane electrode assembly (MEA) can be described as a macro-homogeneous medium with effective transport properties

2. The relevant transport processes in the gas channels (GCs) and the porous layers of the cell are the same: convection, diffusion and capillary transport.

3. Gravitational forces can be neglected.

4. Fluid phases in the porous domains are in local chemical equilibrium.

5. At the PEM/CL interface, local chemical equilibrium between the membrane and the porous electrodes holds.

6. Local thermal equilibrium holds.

7. Gases are ideal.

The kinetics of water evaporation and condensation at the PEM/CL interface influence the water transport through the membrane $[42,5,43,44,6,7,8,9]$. Since the validation of the sorption kinetics is difficult and for the sake of simplicity, the assumptions of chemical and thermal equilibrium at this interface were made. The influence of sorption kinetics on the water transport will be investigated in the future.

The cell is divided into nine layers which are all spatially resolved. The cell geometry, represented in 2D with an along-the-channel domain, is depicted in Fig. 1, along with the physical processes considered in each layer.

\subsection{Governing equations}

The general form of the conservation equations, which are solved for each quantity $\kappa$ (species mass, charge and energy) is derived from the Reynold's transport theorem $[45,46]$. It is given by 

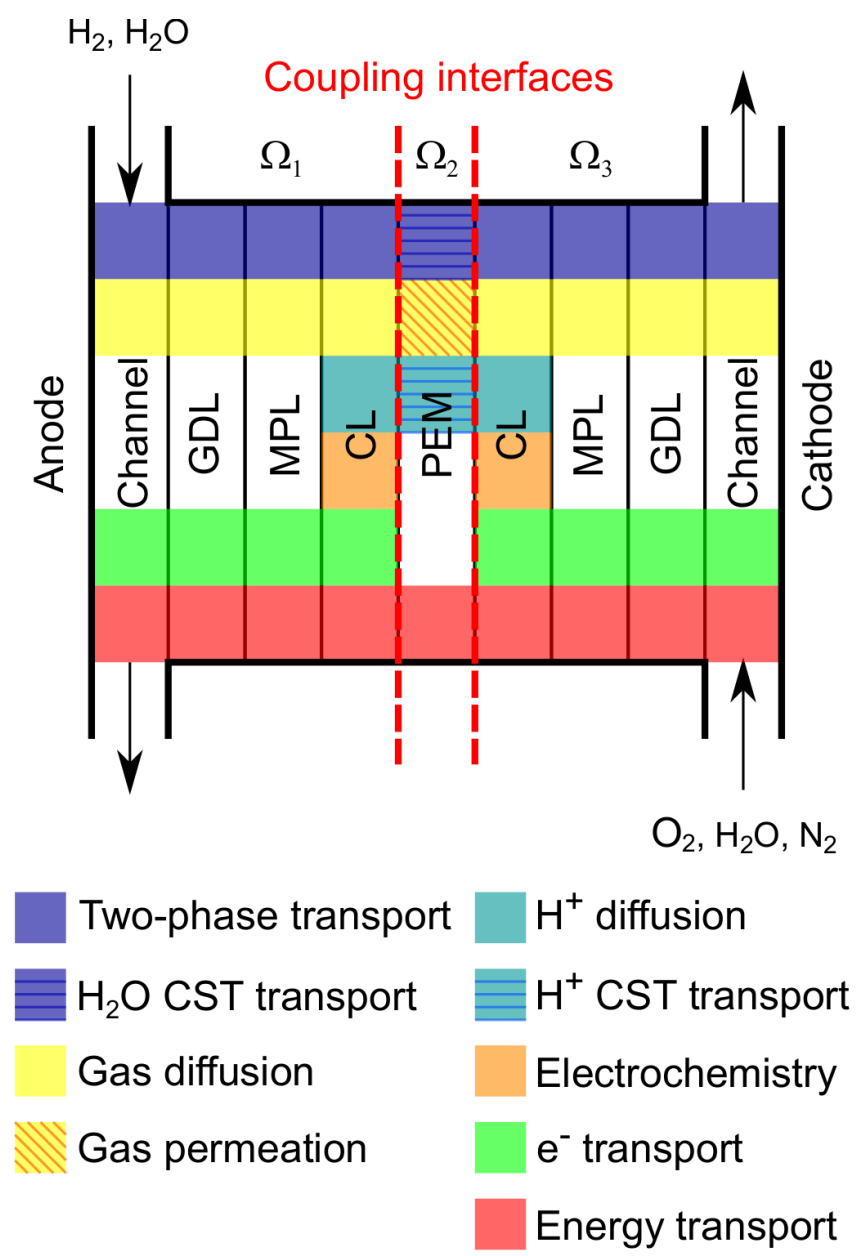

Figure 1: 2D along-the-channel representation of the fuel cell geometry. Colors indicate physical processes. In the PEM, concentrated solution theory (CST) is applied to describe the transport of water and protons. 


$$
\frac{\partial \xi^{\kappa}}{\partial t}+\nabla \cdot \Psi^{\kappa}-q^{\kappa}=0
$$

where $\xi^{\kappa}$ denotes the density or concentration, $\Psi^{\kappa}$ the flux density and $q^{\kappa}$ the supply/production of species $\kappa$ respectively. In the following, they will be discussed separately for the PEM and the porous electrodes.

\subsection{Membrane transport}

To describe the transport of water, protons and dissolved gaseous species in the PEM, the model of Weber and Newman [16], which is based on concentrated solution theory [47] is applied. Since the original formulation applies to a steadystate and the present formulation is transient, in addition to the flux densities, expressions for the concentration $\xi^{\kappa}$ need to be provided. For water, the molar concentration is given by

$$
\xi^{\mathrm{H}_{2} \mathrm{O}}=c^{\mathrm{H}_{2} \mathrm{O}}=\frac{\phi_{P E M} \rho_{P E M, d r y} \lambda^{\mathrm{H}_{2} \mathrm{O}}}{E W} .
$$

Here, $\phi_{P E M}$ denotes the volume fraction of polymer which may be smaller than 1, e.g. if a reinforcement layer is considered. The term $\rho_{P E M, d r y}$ represents the mass density of the dry membrane, neglecting the influence of swelling. The moles of $\mathrm{H}_{2} \mathrm{O}$ per mole of $\mathrm{SO}_{3}{ }^{-}$are represented by $\lambda^{\mathrm{H}_{2} \mathrm{O}}$ and $E W$ denotes the equivalent weight (mass per mole $\mathrm{SO}_{3}{ }^{-}$) of the polymer. The water flux density is calculated as

$$
\begin{aligned}
& \Psi^{\mathrm{H}_{2} \mathrm{O}}=S_{c h}\left[-\frac{\sigma_{\text {ion }} n_{\text {drag }, l}}{\mathrm{~F}} \nabla \Phi_{\text {ion }}-\left(\alpha_{l}+\frac{\sigma_{\text {ion }} n_{\text {drag }, l}^{2}}{\mathrm{~F}^{2}}\right) \nabla \mu^{\mathrm{H}_{2} \mathrm{O}}\right] \\
& +\left(1-S_{c h}\right)\left[-\frac{\sigma_{\text {ion }} n_{\text {drag }, v}}{\mathrm{~F}} \nabla \Phi_{i o n}-\left(\alpha_{v}+\frac{\sigma_{\text {ion }} n_{\text {drag }, v}^{2}}{\mathrm{~F}^{2}}\right) \nabla \mu^{\mathrm{H}_{2} \mathrm{O}}\right] .
\end{aligned}
$$

The symbols $S_{c h}, \sigma_{i o n}$ and $n_{\text {drag }}$ denote the fraction of expanded water channels in the membrane, the ionic conductivity and the electro-osmotic drag coefficient respectively. $\Phi_{i o n}, \alpha$ and $\mu^{\mathrm{H}_{2} \mathrm{O}}$ represent ionic potential, water transport coefficient and the chemical potential of water respectively. The transport 
coefficient $\alpha$ and drag coefficient $n_{\text {drag }}$ take different values for a membrane equilibrated with water vapor (subscript $v$ ) or liquid water (subscript $l$ ). The overall flux density of water is calculated as the superposition of both transport modes, weighted with the fraction of expanded channels $S_{c h}$. In the membrane, no sources or sinks for water are considered. Therefore, the corresponding term $q^{\mathrm{H}_{2} \mathrm{O}}$ is equal to zero.

Assuming electro-neutrality, the storage term for the protonic charge balance vanishes and the flux term is

$$
\begin{aligned}
& \Psi^{\mathrm{H}^{+}}=S_{c h}\left[-\sigma_{i o n} \nabla \Phi_{i o n}-\frac{\sigma_{i o n} n_{\text {drag }, l}}{\mathrm{~F}} \nabla \mu^{\mathrm{H}_{2} \mathrm{O}}\right] \\
+ & \left(1-S_{c h}\right)\left[-\sigma_{i o n} \nabla \Phi_{i o n}-\frac{\sigma_{i o n} n_{\text {drag }, v}}{\mathrm{~F}} \nabla \mu^{\mathrm{H}_{2} \mathrm{O}}\right] .
\end{aligned}
$$

In the membrane, the source/sink term for protons is equal to zero.

The ionic conductivity in $\mathrm{S} \mathrm{m}^{-1}$ is modeled using [10]

$$
\sigma_{\text {ion,PEM }}=\left(0.5139 \lambda^{\mathrm{H}_{2} \mathrm{O}}-0.326\right) \exp \left[1268\left(\frac{1}{303}-\frac{1}{T}\right)\right],
$$

where $\lambda^{\mathrm{H}_{2} \mathrm{O}}$ is determined from the water activity in the gas phase at the PEM/CL interface using the sorption isotherm from [48] with the modification given in [16].

The transport of $\mathrm{O}_{2}$ and $\mathrm{H}_{2}$ through the membrane is based upon dilute solution theory [47] which neglects all interaction but those between the cross-over species and the polymer matrix [16]. The corresponding conservation equations, neglecting sources and sinks, are given by

$$
\frac{\partial \phi_{P E M} c^{\kappa}}{\partial t}+\nabla \cdot\left[S_{c h}\left(-\psi_{l}^{\kappa} \nabla p^{\kappa}\right)+\left(1-S_{c h}\right)\left(-\psi_{v}^{\kappa} \nabla p^{\kappa}\right)\right]=0,
$$

where $p^{\kappa}$ denotes the partial pressure of species $\kappa$. The corresponding permeation coefficients $\psi_{v, l}^{\kappa}$ given in [16] are also used here.

The polymer matrix consists of aqueous and polytetrafluoroethylene (PTFE)like domains. Therefore, the amount of energy stored in the ionomer system will depend on the hydration and is formulated as 


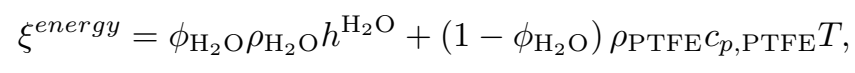

where $c_{p, \mathrm{PTFE}}=960 \mathrm{~J} \mathrm{~kg}^{-1} \mathrm{~K}^{-1}$ is used and the volume fraction of water in the membrane, $\phi_{\mathrm{H}_{2} \mathrm{O}}$, is calculated according to [16]. The transport of energy is assumed to proceed via heat conduction and convection. Therefore, the flux term is given by

$$
\Psi^{\text {energy }}=-\lambda \nabla T+\Psi^{\mathrm{H}_{2} \mathrm{O}} M^{\mathrm{H}_{2} \mathrm{O}} h^{\mathrm{H}_{2} \mathrm{O}} .
$$

The heat conductivity of the PEM in $\mathrm{W} \mathrm{m}^{-1} \mathrm{~K}^{-1}$ is determined using the relation of [49]:

$$
\lambda_{P E M}=0.177+3.7 \times 10^{-3} \lambda^{\mathrm{H}_{2} \mathrm{O}} .
$$

Further, ohmic heating due to proton transport is calculated via

$$
q^{\text {energy }}=-\mathbf{i} \nabla \Phi_{i o n},
$$

where the considered current density is calculated according to Eq. (4).

\subsection{Transport in the porous electrodes}

Compositional multiphase-flow in the electrodes and GCs is described using porous medium theory [46]. All relevant quantities are defined on the basis of the representative elementary volume (REV) [50]. For a system with M different phases consisting of $\mathrm{N}$ components, the storage and flux terms of Eq. (1) for each component $\kappa$ are expressed as [51]

$$
\begin{aligned}
\xi^{\kappa} & =\phi \sum_{\alpha=1}^{\mathrm{M}} \rho_{m o l, \alpha} x_{\alpha}^{\kappa} S_{\alpha} \\
\Psi^{\kappa} & =-\sum_{\alpha=1}^{\mathrm{M}}\left(\rho_{m o l, \alpha} x_{\alpha}^{\kappa} \mathbf{v}_{\alpha}+\mathbf{d}_{\alpha}^{\kappa}\right),
\end{aligned}
$$

where $\mathbf{d}_{\alpha}^{\kappa}$ denotes the diffusive flux of species $\kappa$ in phase $\alpha$ and $\mathbf{v}_{\alpha}$, the phase velocity, is expressed using a multiphase Darcy approach [46, 52]: 


$$
\mathbf{v}_{\alpha}=-\frac{k_{r \alpha}}{\mu_{\alpha}} \mathbf{K} \nabla p_{\alpha}
$$

The relation between the liquid phase pressure $p_{l}$ and gas phase pressure $p_{g}$ is

$$
p_{l}=p_{g}+p_{c}
$$

where the capillary pressure $p_{c}$ is calculated via a standard Leverett approach $[53,39]$ as a function of the liquid phase saturation. For a contact angle $\theta$ smaller $90^{\circ}$

$$
\begin{aligned}
p_{c}= & \sigma^{\text {surface }} \cos (\theta)\left(\frac{\mathrm{K}}{\phi}\right)^{-\frac{1}{2}} \\
& \times\left[1.417(1-S)-2.12(1-S)^{2}+1.263(1-S)^{3}\right],
\end{aligned}
$$

for $\theta>90^{\circ}$,

$$
\begin{aligned}
p_{c}= & \sigma^{\text {surface }} \cos (\theta)\left(\frac{\mathrm{K}}{\phi}\right)^{-\frac{1}{2}} \\
& \times\left[1.417 S-2.12 S^{2}+1.263 S^{3}\right] .
\end{aligned}
$$

The relative permeability of the GDLs, MPLs and CLs is described using a simple power law [54], where the exponent for all layers was estimated to be 2.5:

$$
k_{r \alpha}=S_{\alpha}^{2.5}
$$

The diffusive flux is calculated according to the Stefan-Maxwell equation [55], where

$$
\nabla x_{\alpha}^{i}=\sum_{j=1}^{\mathrm{N}} \frac{c_{\alpha}^{i} c_{\alpha}^{j}}{c_{\alpha}^{2} D_{e f f, \alpha}^{i}}\left(\frac{\mathbf{d}_{\alpha}^{j}}{c_{\alpha}^{j}}-\frac{\mathbf{d}_{\alpha}^{i}}{c^{i} \alpha}\right) .
$$

Effective diffusion coefficients $D_{\text {eff, } \alpha}^{\kappa}$ are calculated with the Fuller-method [56] and the influence of the porous medium is considered using a Bruggemannapproach. The resulting diffusion coefficients in the porous medium are 


$$
D_{p m, \alpha}^{\kappa}=\left(\phi S_{\alpha}\right)^{1.5} D_{\alpha}^{\kappa}
$$

In the gas phase, since the pore radii in the CLs and micro-porous layers (MPLs) are in the nanometer range [57], Knudsen diffusion has to be considered and the effective diffusion coefficient is calculated with a Bosanquet formulation

$$
D_{e f f, g}^{\kappa}=\left(\frac{1}{D_{p m, g}^{\kappa}}+\frac{1}{D_{\text {Knudsen }, g}^{\kappa}}\right)^{-1},
$$

where

$$
D_{\text {Knudsen,g }}^{\kappa}=r_{\text {pore }} \frac{2}{3} \sqrt{\frac{8 \mathrm{R} T}{\pi M^{\kappa}}} .
$$

In addition to the species mass balance equations, the conditions for the local phase presence are formulated as a set of Karush-Kuhn-Tucker (KKT) conditions which are reformulated as non-differential but semi-smooth nonlinear complementarity problems (NCPs) [51]. This approach increases numerical robustness but comes at the cost of two additional degrees of freedom in the system.

In the CLs, the ionomer exists in the form of thin-films covering carbon and platinum particles. The properties of these thin-films may differ significantly from those of a bulk membrane $[58,59]$. Here, proton transport in the CLs is described using Ohm's law (Eq. (23)). Charge may be stored in the electrical double layers. Therefore, the storage term for the protonic charge conservation is

$$
\xi^{\mathrm{H}^{+}}=-C_{D L}\left(\Phi_{\text {elec }}-\Phi_{i o n}\right)
$$

and the flux term is expressed as

$$
\Psi^{\mathrm{H}^{+}}=-\sigma_{e f f}^{\mathrm{H}^{+}} \nabla \Phi_{i o n} .
$$

Proton conductivity in the CLs, $\sigma_{e f f}^{\mathrm{H}^{+}}$, is modeled using a material-dependent empirical relation which describes the dependence on the water activity. A value 
$a_{\text {trans }}^{\mathrm{H}_{2} \mathrm{O}}$ is defined separating the water activity range into two domains. In each domain, an exponential relation $[58,60]\left(f_{1}\right.$ or $f_{2}$ with the parameters $A, B$ and $C)$ is used. The function is required to be continuous for $a^{\mathrm{H}_{2} \mathrm{O}}=a_{\text {trans }}^{\mathrm{H}_{2} \mathrm{O}}$ :

$$
\begin{gathered}
f_{1}\left(a^{\mathrm{H}_{2} \mathrm{O}}\right)=A \times \exp \left(B a^{\mathrm{H}_{2} \mathrm{O}}\right) \\
f_{2}\left(a^{\mathrm{H}_{2} \mathrm{O}}\right)=A \times \exp \left[(B-C) a_{\text {trans }}^{\mathrm{H}_{2} \mathrm{O}}\right] \exp \left(C a^{\mathrm{H}_{2} \mathrm{O}}\right) \\
\sigma_{\text {eff,CL }}^{\mathrm{H}^{+}}=\min \left(f_{1}, f_{2}\right) .
\end{gathered}
$$

Electron transport in the bipolar plates and the solid matrix of the porous electrodes is described using Ohm's law. Outside the CLs, the balance equation for electrons is reduced to the flux term:

$$
\Psi^{\mathrm{e}^{-}}=-\sigma_{e f f}^{\mathrm{e}^{-}} \nabla \Phi_{\text {elec }}
$$

The storage term describing the charging and discharging of the double layers for the electrical charge balance is the same as for the protons (Eq. (22)) with opposite sign.

Assumption of local thermal equilibrium between the solid, gas and liquid phase allows the energy balance of the compositional multi-phase system to be written as a single equation [51]. Storage and flux term are given by

$$
\xi^{\text {energy }}=\phi \sum_{\alpha=1}^{\mathrm{M}} \rho_{\alpha} u_{\alpha} S_{\alpha}+(1-\phi) \rho_{s} c_{p, s} T
$$

and

$$
\Psi^{\text {energy }}=-\sum_{\alpha=1}^{\mathrm{M}} \frac{k_{r \alpha}}{\mu_{\alpha}} \rho_{\alpha} h_{\alpha} \mathbf{K} \nabla p_{\alpha}-\sum_{\kappa=1}^{\mathrm{N}} \sum_{\alpha=1}^{\mathrm{M}} h_{\alpha}^{\kappa} M^{\kappa} \mathbf{d}_{\alpha}^{\kappa}-\lambda_{p m} \nabla T .
$$

The thermal conductivity of the porous medium is modeled using the approach of [61]

$$
\lambda_{p m}=\lambda_{d r y}+\sqrt{S_{l}}\left(\lambda_{w e t}-\lambda_{d r y}\right)
$$


where

$$
\lambda_{d r y}=\lambda_{s}^{(1-\phi)} \lambda_{g}^{\phi}
$$

and

$$
\lambda_{w e t}=\lambda_{s}^{(1-\phi)} \lambda_{l}^{\phi}
$$

denote the thermal conductivity of the gas- and liquid-filled porous medium respectively. The thermal conductivity of the gas phase $\lambda_{g}$ is is calculated from the pure gas phase species thermal conductivities and the phase composition, for $\lambda_{l}$, the value for liquid water according to [62] is used. The thermal conductivity of the solid phase, $\lambda_{s}$, is fitted to simulation results of [63]. With a value of $128.95 \mathrm{~W} \mathrm{~m}^{-1} \mathrm{~K}^{-1}$, the effective thermal conductivity is $\sim 0.9$ if no liquid water is present.

Since the thermal conductivity of the liquid phase is higher than the one of the gas phase, the effective thermal conductivity of the porous media increases with the liquid saturation. With the relation above, the effective thermal conductivity of the fully saturated porous medium, is $\sim 5 \mathrm{~W} \mathrm{~m}^{-1} \mathrm{~K}^{-1}$.

The heat production in the CLs due to half-cell reaction $i$ is calculated according to [64]

$$
q^{\text {energy, } i}=-\left|r^{i}\right|\left(\Pi^{i}-\left|\eta^{i}\right|\right),
$$

where the Peltier coefficient $\Pi^{i}$ is defined as [2]

$$
\Pi^{i}=\frac{T \Delta s^{i}}{n \mathrm{~F}} .
$$

Again, ohmic heating in the CLs is considered using Eq. (10), where the current density is calculated with Eq. (23).

\subsection{Electrochemistry}

The hydrogen oxidation reaction (HOR) is formulated as: 


$$
\mathrm{H}_{2} \rightleftharpoons 2 \mathrm{H}^{+}+2 \mathrm{e}^{-} .
$$

It is modeled using BV kinetics. The volumetric reaction rate is expressed as

$$
\begin{aligned}
r^{\mathrm{HOR}}= & \frac{p^{\mathrm{H}_{2}}}{p_{\text {ref }}^{\mathrm{H}_{2}}} E C S A_{\text {Anode }} i^{0, \mathrm{HOR}} \\
& \times\left[\exp \left(\frac{\alpha^{f} n \mathrm{~F} \eta^{\mathrm{HOR}}}{\mathrm{R} T}\right)-\exp \left(-\frac{\alpha^{r} n \mathrm{~F} \eta^{\mathrm{HOR}}}{\mathrm{R} T}\right)\right],
\end{aligned}
$$

where $\alpha^{f}=\alpha^{r}=0.5[65], i^{0, \mathrm{HOR}}=3 \times 10^{3} \mathrm{~A} \mathrm{~m}^{-2}[65]$ and $n=2$. The overpotential of reaction $i$ is calculated with

$$
\eta^{i}=\Phi_{e l e c}-\Phi_{i o n}-E^{0, i}
$$

For the HOR, $E^{0, \mathrm{HOR}}$ was chosen as the reference potential and is therefore equal to zero.

The ORR is formulated as

$$
\frac{1}{2} \mathrm{O}_{2}+2 \mathrm{H}^{+}+2 \mathrm{e}^{-} \rightleftharpoons \mathrm{H}_{2} \mathrm{O}
$$

Reaction kinetics. In this reaction, the water-, proton- and electron activities are assumed to be unity. According to the Nernst equation, the equilibrium voltage is given by

$$
\begin{aligned}
E^{0, \text { ORR }}= & 1.23-9 \times 10^{-4}(T-298.15) \\
& -\frac{\mathrm{R} T}{n \mathrm{~F}} \ln \left(\frac{1}{\left(a^{\mathrm{O}_{2}}\right)^{v^{\mathrm{O}_{2}}}}\right)
\end{aligned}
$$

where $n=2$ and $v^{\mathrm{O}_{2}}=0.5$ is the stoichiometry coefficient of oxygen.

Again, BV kinetics are used to describe the reaction. To incorporate the doubling of the Tafel slope, the approach of $[21,22]$ is adopted here and two different sets of BV parameters, depending on the cell voltage are employed. To distinguish between the two voltage regimes, the electrode potential is compared to a defined transition overpotential $\eta_{\text {trans }}^{\mathrm{ORR}}=0.76 \mathrm{~V}$ : 


$$
\begin{aligned}
& \text { if } \Phi_{\text {elec }}-\Phi_{\text {ion }} \geq \eta_{\text {trans }}^{\mathrm{ORR}} \Rightarrow \text { high voltage regime } \\
& \text { if } \Phi_{\text {elec }}-\Phi_{\text {ion }}<\eta_{\text {trans }}^{\mathrm{ORR}} \Rightarrow \text { low voltage regime. }
\end{aligned}
$$

In the high voltage regime, $\alpha_{\text {high }}^{f}=\alpha_{\text {high }}^{r}=0.5$ is used, while $\alpha_{\text {low }}^{f}=\alpha_{\text {low }}^{r}=$ $0.25[66,67,18]$. The exchange current density in the high voltage regime is calculated with $[22]$

$$
i_{\text {high }}^{0}=i_{\text {ref }}^{0} \exp \left[\frac{-E_{a c t}}{\mathrm{RT}}\left(\frac{1}{T}-\frac{1}{323}\right)\right] .
$$

The exchange current density of the low voltage regime is calculated as

$$
i_{\text {low }}^{0}=i_{\text {high }}^{0} \exp \left[\left(\alpha_{\text {low }}^{f}-\alpha_{\text {high }}^{f}\right) \frac{n \mathrm{~F}}{\mathrm{RT}}\left(\eta_{\text {trans }}^{\text {ORR }}-E^{0, \mathrm{ORR}}\right)\right] .
$$

to obtain a continuous reaction rate at the transition overpotential.

Assuming the ORR reaction rate to be proportional to the square root of the oxygen concentration at the platinum surface $c_{\mathrm{Pt}}^{\mathrm{O}_{2}}$, it is formulated as

$$
r^{\mathrm{ORR}}=\sqrt{c_{\mathrm{Pt}}^{\mathrm{O}_{2}}} k^{\mathrm{ORR}} .
$$

The rate 'constant' of the ORR is given by 


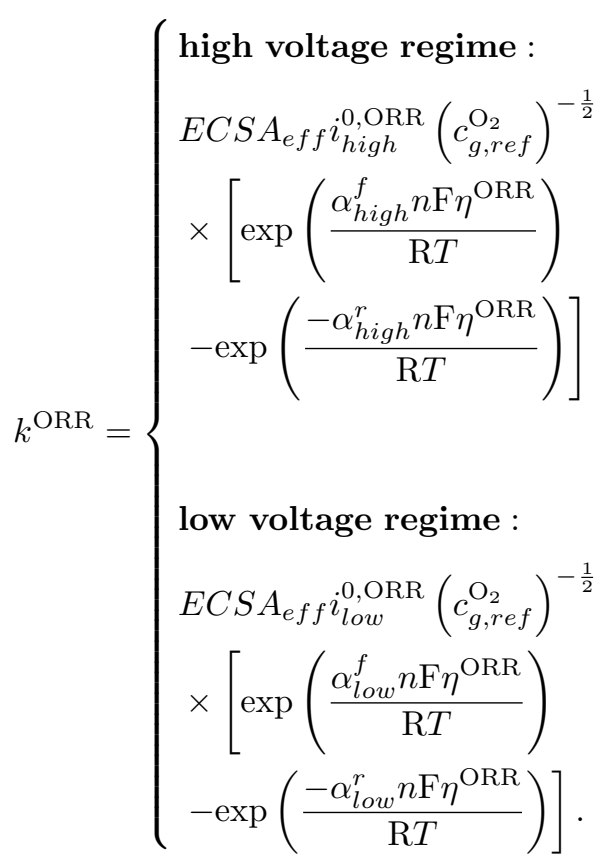

Ionomer film model. In order to react, $\mathrm{O}_{2}$ needs to reach the catalyst surface. Since water and ionomer films pose a resistance to transport to the active sites a model, similar to [35], is employed to determine the $\mathrm{O}_{2}$ concentration on the platinum particles. It incorporates the following resistances:

1. Transport resistance due to water films covering the ionomer

2. Diffusion through the ionomer

3. A lumped interfacial resistance describing the humidity-dependent dissolution into the ionomer and the interfacial resistance at the platinum / ionomer interface [68].

The flux of oxygen to the platinum surface is

$$
\Psi^{\mathrm{O}_{2}}=\frac{c_{g}^{\mathrm{O}_{2}}-c_{\mathrm{Pt}}^{\mathrm{O}_{2}}}{R},
$$

where $R$ denotes the sum of the single transport resistances. It is calculated as 


$$
R=\left(R_{l}+R_{d i f f}+R_{i n t}\right)
$$

with

$$
\begin{aligned}
R_{l} & =A \sqrt[3]{S_{l}} \\
R_{\text {diff }} & =\frac{\delta_{i o n}}{D_{i o n}^{\mathrm{O}_{2}}} \\
R_{\text {int }} & =B \exp \left(C a^{\mathrm{H}_{2} \mathrm{O}}\right),
\end{aligned}
$$

where $A, B$ and $C$ are fitted constants. Recently the thickness of the ionomer film in commercial MEAs was experimentally determined to be between 7 and $9 \mathrm{~nm}$ [69]. Thus, $\delta_{\text {ion }}$, the thickness of the ionomer film, is set to $7 \mathrm{~nm}$. The effective diffusion coefficient in $\mathrm{m}^{2} \mathrm{~s}^{-1}$ for $\mathrm{O}_{2}$ in Nafion ${ }^{\circledR}$ is calculated as [70]

$$
D_{i o n}^{\mathrm{O}_{2}}=17.45 \times 10^{-10} \exp \left(\frac{-1514}{T}\right) .
$$

The flux of oxygen calculated with Eq. (45) is equal to the volumetric BV rate of the ORR (Eq. (43)). Therefore,

$$
\Psi^{\mathrm{O}_{2}}=\frac{r^{\mathrm{ORR}}}{n \mathrm{~F} E C S A_{\text {eff }}}=\frac{\sqrt{c_{\mathrm{Pt}}^{\mathrm{O}_{2}}} k^{\mathrm{ORR}}}{n \mathrm{~F} E C S A_{\text {eff }}} .
$$

Combination of Eq. (45) and Eq. (51) yields

$$
n \mathrm{~F} E C S A_{e f f} c_{\mathrm{Pt}}^{\mathrm{O}_{2}}+k^{\mathrm{ORR}} R \sqrt{c_{\mathrm{Pt}}^{\mathrm{O}_{2}}}-n \mathrm{~F} E C S A_{e f f} c_{g}^{\mathrm{O}_{2}}=0,
$$

which can be solved for $r^{\mathrm{ORR}}$. The final expression for the reaction rate of the ORR, taking into account oxygen transport resistances is then

$$
r^{\mathrm{ORR}}=\frac{-R k^{\mathrm{ORR}}+\sqrt{4 E C S A_{e f f} n^{2} \mathrm{~F}^{2} c_{g}^{\mathrm{O}_{2}}+R^{2}\left(k^{\mathrm{ORR}}\right)^{2}}}{2 n \mathrm{FECSA} A_{e f f}} k^{\mathrm{ORR}}
$$


Platinum oxide formation. In this model, platinum oxides which are formed on the platinum surface at high potentials are considered as site blockers, reducing the active area [71]. The reaction considered is

$$
\mathrm{Pt}+\mathrm{H}_{2} \mathrm{O} \rightleftharpoons \mathrm{PtO}+2 \mathrm{H}^{+}+2 \mathrm{e}^{-},
$$

with the estimated equilibrium voltage $E^{0, \text { PtOx }}=0.81 \mathrm{~V}$. An additional balance equation is solved in the cathode CL describing the oxide coverage of the active area:

$$
\frac{\partial \theta^{\mathrm{PtOx}}}{\partial t}-q^{\mathrm{PtOx}}=0 .
$$

The source- and sink term of Eq. (55) is then expressed via [71]

$$
\begin{aligned}
& q^{\mathrm{PtOX}}=k^{\mathrm{PtOX}}\left[a^{\mathrm{H}_{2} \mathrm{O}} \exp \left(\frac{-E_{a c t}^{\mathrm{PtOX}}}{\mathrm{R} T} \theta^{\mathrm{PtOX}}\right)\right. \\
& \times\left(1-\theta^{\mathrm{PtOX}}\right) \exp \left(\frac{\alpha^{\mathrm{PtOX}} \mathrm{F} \eta^{\mathrm{PtOX}}}{\mathrm{R} T}\right) \\
& \left.-\theta^{\mathrm{PtOx}} \exp \left(-\frac{\alpha^{\mathrm{PtOX}} \mathrm{F} \eta^{\mathrm{PtOX}}}{\mathrm{R} T}\right)\right],
\end{aligned}
$$

where the rate constant of platinum oxide formation, $k^{\mathrm{PtOX}}$, is assumed to be $0.0128 \mathrm{~s}^{-1}$. The original formulation was extended to take into account the dependence of the platinum oxide formation on the water activity [72]. This is represented using an Arrhenius expression which increases the forward reaction kinetics with higher water activity similar to [73]. The activation energy $E_{a c t}^{\mathrm{PtOX}}$ was estimated to be $10^{4} \mathrm{~J} \mathrm{~mol}^{-1}$ and the transfer coefficient $\alpha^{\text {PtOX }}=0.5$.

The contributions of the platinum oxide model to the proton-, electron and water balance are expressed as

$$
\begin{aligned}
q^{\mathrm{H}^{+}}=q^{\mathrm{e}^{-}} & =E C S A_{\text {eff }} n 2.1 q^{\mathrm{PtOX}} \\
q^{\mathrm{H}_{2} \mathrm{O}} & =E C S A_{\text {eff }} \frac{2.1}{\mathrm{~F}} q^{\mathrm{PtOX}},
\end{aligned}
$$

where the factor 2.1 denotes the charge, which is transferred per platinum surface [74], $n=2$ and the effective electrochemical active surface area is calculated with 


$$
E C S A_{e f f}=\left(1-\theta^{\mathrm{PtOX}}\right) E C S A .
$$

For ECSA, a constant value is employed.

\subsection{Boundary- and coupling conditions}

In order to be as close to the experimental conditions as possible, the gas pressure is set at the outlets of the GCs using a Dirichlet condition. This corresponds to operation with a fixed back pressure. Further, for the mass balances, outflow conditions are specified. At the inlets, the mole fractions for all species are prescribed except one. For this remaining species, a Neumann condition is applied. This way, the gas phase composition and the mass flux into the modeling domain are controlled simultaneously. The flux of species $\kappa$ into the cell is calculated from the current $I$ and a lambda control parameter $\lambda^{\text {flux, } \kappa}$ using

$$
\Psi^{\kappa}=\frac{\lambda^{f l u x, \kappa} \max \left(I_{\text {min }}, I\right)}{n \mathrm{~F} A_{\text {inlet }}} \mathbf{n} .
$$

If the current is below a given threshold, the fluxes are calculated according to $I_{\min }$.

For the electrical charge balance, the potential at the anodic interface between GC and bipolar plate (BP) is set to zero as reference. At the cathode side, the boundary condition depends on the operating mode. In potentiostatic mode, a Dirichlet condition is used for the electrode potential at the cathode GC/BP interface, while in galvanostatic mode, a Neumann condition corresponding to the cell current density is applied.

At the coupling interfaces, local thermodynamic equilibrium is assumed. Therefore, the ionic potential, the temperature and the partial pressures of the

cross-over gases are continuous at the interfaces. For the water balance, the chemical potential is calculated from the thermodynamic state inside the CL using

$$
\mu^{\mathrm{H}_{2} \mathrm{O}}=\mathrm{R} T \ln \left(a^{\mathrm{H}_{2} \mathrm{O}}\right)+S_{l, C L} v^{\mathrm{H}_{2} \mathrm{O}} p
$$


With this approach, Schroeder's paradox is treated in a macroscopic way. If $S_{l, C L}=0$, the PEM is in contact with a vapor phase and the second term of Eq. (60) vanishes. For $S_{l, C L}=1$, the membrane is in complete contact with a liquid phase and the water uptake is higher. In between, a linear interpolation is employed.

\section{Numerical framework}

The equations presented in Section 2 are implemented into a new numerical framework: NEOPARD-X ${ }^{1}$. It is designed as a flexible framework for transient 2D and 3D simulations, currently applied to the simulation of PEMFCs, direct-methanol fuel cells (DMFCs) and solid oxide electrolyzers (SOECs). NEOPARD-X is based on DUNE [75] [76], Dumu ${ }^{\mathrm{X}}$ [77], Dune PDE-Lab, UG [78], Multidomain and Multidomaingrid [79] [80].

DUNE (Distributed and Unified Numerics Environment), is a modular toolbox for solving of partial differential equations with grid-based methods and Dumu $^{\mathrm{X}}$ (DUNE for Multi-Phase, Component, Scale, Physics, ... flow and transport in porous media) is a numerical framework for flow and transport processes in porous media. Both codes are open-source software. NEOPARD-X extends the Dumu $^{\mathrm{X}}$ capabilities to describe ionic and electrical charge transport, detailed electrochemistry and ionomer properties and allows for transient simulations under realistic boundary conditions such as

- constant flux or lambda-control with fixed back pressure

- potentio- or galvanostatic operation

- co- and counter flow

- polarization curves, EIS, CV

\footnotetext{
${ }^{1}$ Numerical Environment for the Optimization of Performance And Reduction of Degradation of X where X stands for an energy conversion device, e.g. fuel cell or electrolyzer.
} 
The model geometry can be changed to a 2D channel-rib or full 3D setup where the channel-rib dimension is resolved along the channel. Spatial parameters like permeability, porosity, contact angle, effective electrical- and heat conductivity are specified from an input file for each layer individually. In so-called 'fluid systems', the thermodynamic properties of the relevant species $\left(\mathrm{H}_{2}, \mathrm{O}_{2}, \mathrm{H}_{2} \mathrm{O}, \mathrm{N}_{2}, \ldots\right)$ are gathered and effective properties of the gas and liquid phase are calculated.

For the spatial discretization of the equations presented in Section 2, the box method [81] is applied. It is a combination of the finite-volume (FV) and the finite-element (FE) method and unites the advantages of both: local mass conservation and the utilization of unstructured grids. For the time discretization the fully implicit Euler scheme is applied.

Using the Multidomain capabilities, the fuel cell sandwich is divided into three sub-domains: the two electrodes (GCs, GDLs, MPLs and CLs) and the PEM. For each sub domain, a different set of partial differential equations is solved which represents the underlying physics. The three domains are coupled to each other at the CL/PEM interfaces. These interfaces represent interior boundaries where coupling conditions need to be formulated.

For the rapid calculation of the cell impedance, the potential step method of [82] is used. To simulate an impedance spectrum, depending on the operating mode, the cell current density or voltage is ramped to the desired value and held constant until a the steady state is reached. Then, a rapid current- or voltage ramp at a rate of $2 \times 10^{10} \mathrm{~A} \mathrm{~m}^{-2} \mathrm{~s}^{-1}$ or $5 \times 10^{5} \mathrm{~V} \mathrm{~s}^{-1}$ respectively, is simulated. Subsequently, the current or voltage is again held constant until the steady state is reached. The impedance is obtained from a Fourier transformation [82] of the time domain data of current density and voltage.

\section{Experiments}

For the model validation, dedicated PEMFC experiments were performed using home-made gold coated stainless steel cells with $5 \times 5 \mathrm{~cm}^{2}$ active area, 
a single serpentine flow field and co-flow configuration. In order to measure the current density distribution a DLR home-made segmented board with $7 \times 7$ segments and $5 \times 5 \mathrm{~cm}^{2}$ area was installed at the anode side between the gold coated stainless steel cell and the MEA. It consists of an array of current collectors placed on the surface of an epoxy-glass resin matrix. For the local current measurement resistors are integrated in the printed circuit board; for details on the segmented board the reader is referred to $[83,84,85,86,87]$.

The in-house developed test stand for single cell PEMFC measurements is controlled by programmable logic controllers allowing automatic control of the input and output conditions, e.g. the pressure, temperature, gas flow rates as well as humidity. In this study, voltage data and test bench parameters were acquired every $10 \mathrm{~s}$. A commercial electronic load from Zentro Elektrik was used. The cells were operated at $80^{\circ} \mathrm{C}$ cell temperature using $\mathrm{H}_{2}(5 \mathrm{~N}$ purity) and pressurized and filtered air. The relative humidity of the feed gases was set by adjusting the temperature of the bubblers used as gas humidifiers. Water condensation in the gas connector tubes was avoided by keeping their temperatures $5^{\circ} \mathrm{C}$ above the bubbler temperature. Before starting the first diagnostics the MEA was conditioned for several hours at $0.8 \mathrm{~A} \mathrm{~cm}^{-2}$. Operation conditions used in this paper are indicated in Table 1.

The test object was a prototype MEA with $\mathrm{Pt} / \mathrm{C}$ catalysts and a Nafion XL membrane developed by EWii Fuel Cells for stationary application in the frame of the FCH JU SecondAct project (Grant No. 621216). The EIS have been recorded with an IM6e electrochemical workstation and a PP241 power potentiostat from Zahner elektrik $\mathrm{GmbH}$ in galvanostatic mode at $5 \mathrm{~A} \mathrm{~cm}^{-2}$ in the frequency range $100 \mathrm{mHz}-100 \mathrm{kHz}$.

\section{Results}

\subsection{Cell performance and water management}

In order to validate the model, simulation results are compared to the experimentally measured polarization curves at different operating conditions listed 
Table 1: Experimental operating conditions.

$\begin{array}{cccc}\text { Condition } & p_{\text {anode }} \text { cathode } / \mathrm{Pa} & \mathrm{RH} / \% & \lambda^{\text {flux }, \mathrm{H}_{2} / \mathrm{O}_{2}} /- \\ \mathbf{1} & 1.46 \times 10^{5} / 1.427 \times 10^{5} & 30 & 1.5 / 2 \\ \mathbf{2} & 1.46 \times 10^{5} / 1.427 \times 10^{5} & 50 & 1.5 / 2 \\ \mathbf{3} & 1.46 \times 10^{5} / 1.427 \times 10^{5} & 90 & 1.5 / 2 \\ \mathbf{4} & 2 \times 10^{5} / 2 \times 10^{5} & 50 & 1.5 / 2 \\ \mathbf{5} & 1.46 \times 10^{5} / 1.427 \times 10^{5} & 50 & 4 / 4\end{array}$

in Table 1. All measurements where carried out in co-flow mode at $353.15 \mathrm{~K}$.

The model parameters used for the simulations are given in Table 2.

Table 2: Model parameters used for model validation.

Spatial parameters:

$\begin{array}{lll}\mathbf{K}_{\text {channel }}=\mathbf{K}_{\text {inlet }}=\mathbf{K}_{\text {outlet }}=1.23 \times 10^{-8} & \mathrm{~m}^{2} & \text { fitted } \\ \mathbf{K}_{G D L}=1.8 \times 10^{-11} & \mathrm{~m}^{2} & \text { estimated } \\ \mathbf{K}_{M P L}=3.33 \times 10^{-15} & \mathrm{~m}^{2} & \text { estimated } \\ \mathbf{K}_{C L}=2 \times 10^{-15} & \mathrm{~m}^{2} & \text { estimated } \\ \phi_{\text {channel }}=\phi_{\text {inlet }}=\phi_{\text {outlet }}=\phi_{\text {tube }}=1 & & \\ \phi_{G D L}=0.625 & & \text { estimated } \\ \phi_{M P L}=0.25 & & \text { estimated } \\ \phi_{C L}=0.38 & & \text { estimated } \\ r_{\text {pore }, \text { channel }}=r_{\text {pore }, \text { tube }}=1 \times 10^{-3} & \mathrm{~m} & \text { estimated } \\ r_{\text {pore }, \text { inlet }}=r_{\text {pore }, \text { outlet }}=1 \times 10^{-3} & \mathrm{~m} & \text { estimated } \\ r_{\text {pore }, \text { GDL }}=2.5 \times 10^{-6} & \mathrm{~m} & \text { estimated } \\ r_{\text {pore }, M P L}=30 \times 10^{-9} & \mathrm{~m} & \text { estimated } \\ r_{\text {pore }, C L}=20 \times 10^{-9} & \mathrm{~m} & \text { estimated } \\ \theta_{\text {channel }}=\theta_{\text {inlet }}=\theta_{\text {outlet }}=\theta_{\text {tube }}=112 & \circ & \text { estimated } \\ \theta_{G D L}=104 & \circ & {[88]^{1}}\end{array}$

${ }^{1}$ value for SGL $24 \mathrm{BC}$ 
$\theta_{M P L}=94$

$\theta_{C L}=93$

$\phi_{\text {ion }, C L}=0.4$

$\phi_{\text {ion, } P E M}=1$

Lambda control:

$i_{\text {min }}=2000$

$\lambda^{\text {flux }, \mathrm{O}_{2}}=2 / 4$

$\lambda^{\text {flux }, \mathrm{H}_{2}}=1.5 / 4$

ORR:

$i_{\text {ref }}^{0}=6.6 \times 10^{-4}$

$E_{\text {act }}=2.77 \times 10^{4}$

$\alpha_{\text {high }}^{f}=\alpha_{\text {high }}^{r}=0.5$

$\alpha_{\text {low }}^{f}=\alpha_{\text {low }}^{r}=0.25$

$\eta_{\text {trans }}^{\mathrm{ORR}}=0.76$

Platinum oxide:

$E^{0, \mathrm{PtOx}}=0.81$

$\alpha^{\mathrm{PtOx}}=0.5$

$k^{\mathrm{PtOx}}=0.0128$

HOR:

$i^{0, \mathrm{HOR}}=3 \times 10^{3}$

$\alpha^{f}=\alpha^{r}=0.5$

ECSA:

$E C S A=1.26 \times 10^{7}$

Double layers:

$C_{D L, \text { anode }}=C_{D L, \text { cathode }}=3.4 \times 10^{7}$

CL conductivity:

$A=1.5 \times 10^{-2}$

$B=2$ $\circ$

$\circ$

$\mathrm{A} \mathrm{m} \mathrm{m}^{-2}$

$\mathrm{A} \mathrm{m}^{-2} \quad$ fitted

$\mathrm{J} \mathrm{mol}^{-1} \quad[20]$

fitted

V fitted

V fitted

fitted

$\mathrm{s}^{-1} \quad$ fitted

A m ${ }^{-2} \quad[65]$

$\mathrm{m}^{2} \mathrm{~m}^{-3}$ measurement ${ }^{2}$

$\mathrm{F} \mathrm{m}^{-3} \quad$ fitted

$\mathrm{S} \mathrm{m}^{-1} \quad$ fitted

fitted

${ }^{2}$ corresponds to a $\mathrm{Pt}$ loading of $0.6 \mathrm{mg} \mathrm{cm}-2$ 
$C=5$

fitted

$\underline{\text { Ionomer film model: }}$
$\delta_{\text {ion }}=7 \times 10^{-9}$
m fitted
$A=100$
$\mathrm{s} \mathrm{m}^{-1} \quad$ fitted
$B=4.2 \times 10^{4}$
$\mathrm{s} \mathrm{m}^{-1} \quad$ fitted
$C=-3.9$
fitted

Fig. 2 shows the experimental and simulated polarization curves for the test conditions in linear and logarithmic current density scale.

With a single set of parameters, the model is able to reproduce the experimental polarization curves at different relative humidities, pressures and stoichiometries.

For a PEMFC model, this capability is most important in order to allow predictive modeling and has seldom been achieved in literature. Many published cell models are validated in only one or two operating conditions. In [89], validation is performed for two flow field designs, operation with air and pure oxygen and various values of relative humidity and stoichiometric factors. However, since the model is not transient, comparison with the experiments is only achieved at few different current densities. Validation for different temperatures and pressures is performed in [90] while in [91] the model is validated against experiments with varying relative humidity. The model presented in [92] is validated with current density and temperature distributions under various operating conditions and for two different Pt loadings. Further, the predicted liquid water distribution is compared to neutron imaging data. In comparison, the present model is validated against experiments at various relative humidities, stoichiometry factors, and pressures. In addition to the validation at steady state, the transient response of the cell model is compared to experimentally measured impedance data. Therefore, to the authors knowledge, the current model can be considered to be among the best validated models published today. 

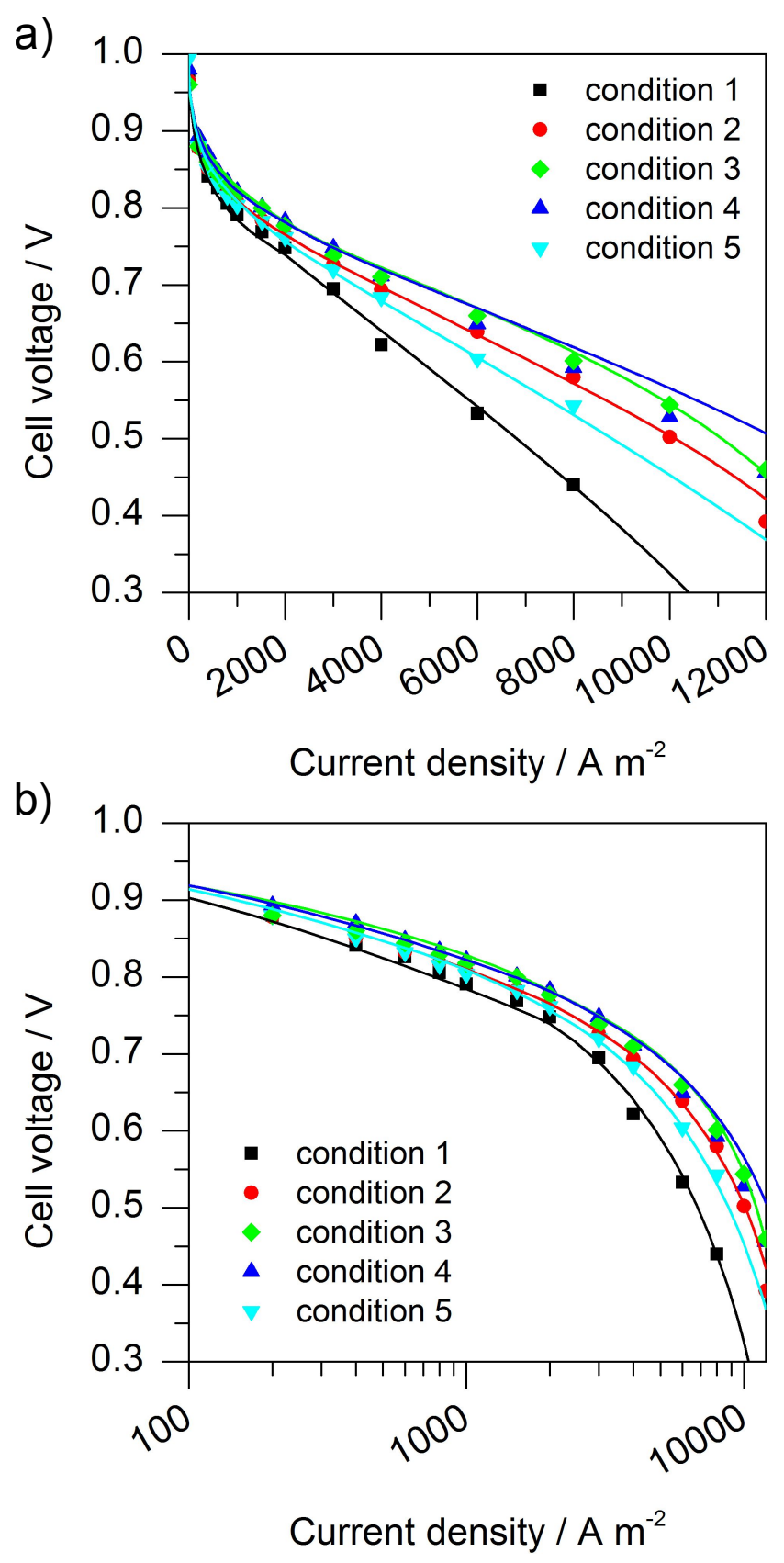

Figure 2: Experimental and simulated polarization curves at various operating conditions. a) linear current density scale, b) logarithmic current density scale. 
Comparing conditions 1-3, an increase of cell performance with increasing humidification is observed. Further, an increase of the gas flow rates may be detrimental to the performance. This becomes clear when conditions 2 and 5 are compared. In both cases, the relative humidity of the inlet gases is $50 \%$. Only the reactant stoichiometries and therefore the flow rates are increased in condition 5. An increase in reactant concentration inside the cell should lead to improved performance. However, this effect is outweighed by the excessive drying of the ionomer in this case. Only the pressure dependence of the cell performance at high current density is slightly overestimated by the model. This might be due to the fact that the ORR reaction rate is assumed to be proportional to $\sqrt{c_{\mathrm{Pt}}^{\mathrm{O}_{2}}}$ (Eq. (43)) disregarding the value of the current density. This dependency yields good results for low and medium current densities but for high currents, a transition to a direct proportionality is expected if oxygen absorption becomes the rate determining step for the ORR. In Fig. 2 b), for all conditions, a doubling of the Tafel slope below $\sim 0.75 \mathrm{~V}$ can be observed and good agreement between measurement and model for low current densities is achieved.

The strong influence of humidification on the cell performance is well known and has been investigated in detail in the literature [93, 94, 95]. With the presented model, these experimental findings can be explained from theoretical considerations. Humidity dependent ionic conductivity in the PEM and CLs in combination with the ionomer film model and a rigorous multiphase-treatment allows the model to reproduce and rationalize the experimental observations.

There are two main reasons for the low cell performance in conditions where dry inlet gases are applied. Firstly, in co-flow mode, humidification of the ionomer close to the gas inlet is low. This increases ohmic losses and reduces the local performance. Along the channel, humidification is improved as more and more water, produced in the ORR, accumulates in the ionomer and the gas stream. This results in rising cell performance towards the gas outlets.

Secondly, in dry conditions, the proton penetration depth into the CL is reduced since the ionic conductivity in the CLs is extremely low (Eq. (26)). 
Therefore, the catalyst utilization in the CLs is small. This demonstrates the necessity to resolve the CLs in the through plane direction in order to obtain realistic simulation results.

Both effects are less pronounced with increasing humidification of the inlet gases (see Fig. 3). Gradients of the current density along the channel and the ORR reaction rate in the through-plane direction are reduced significantly at $90 \%$ relative humidity.

To further analyze the water management of PEMFCs, simulations at 50\% relative humidity in co- and counter-flow mode are compared to each other. Fig. 4 a) and b) show the simulated distribution of the water activity in the anode and cathode along with the distribution of the current density and the water flux density in the PEM at 0.6 V. In Fig. 4 c), the corresponding polarization curves are depicted.

In the cathode, water accumulates along the channel due to the ORR and the water activity is high close to the cathode outlet. In co-flow mode, the trend for the anode from inlet to outlet is the same. Since water concentration gradients across the PEM are small, the water cross-over is comparably small. In counter-flow mode, the model predicts efficient internal humidification as proposed by [41]. The highly humidified cathode outlet is next to the dry anode inlet leading to strong water cross-over in this part of the cell. The humidification of the anode is higher which, in turn, amplifies humidification of the dry cathode inlet. Therefore, the overall humidification inside the cell is improved and the cell current density at $0.6 \mathrm{~V}$ increases from $\sim 7000 \mathrm{~A} \mathrm{~m}^{-2}$ in co-flow to $\sim 8000 \mathrm{~A} \mathrm{~m}^{-2}$ in counter-flow mode.

Similar to the findings in [41], the model shows that back-diffusion of product water to the anode is the dominant process for water management in the cell. It allows internal humidification of and prevents drying out of the anode. This trend results from the competition of electro-osmosis and transport due to chemical potential gradients (see Eq. (3)). Close to the anode inlet, the chemical potential gradient across the membrane dominates the transport and water flows from the cathode to the anode. Along the channel, the local current 
a)

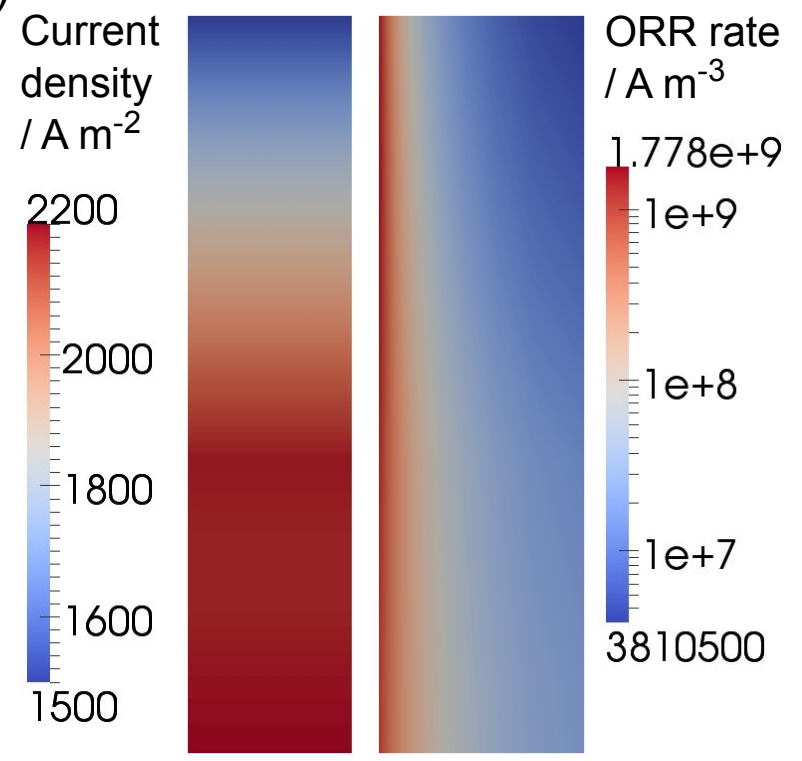

b)

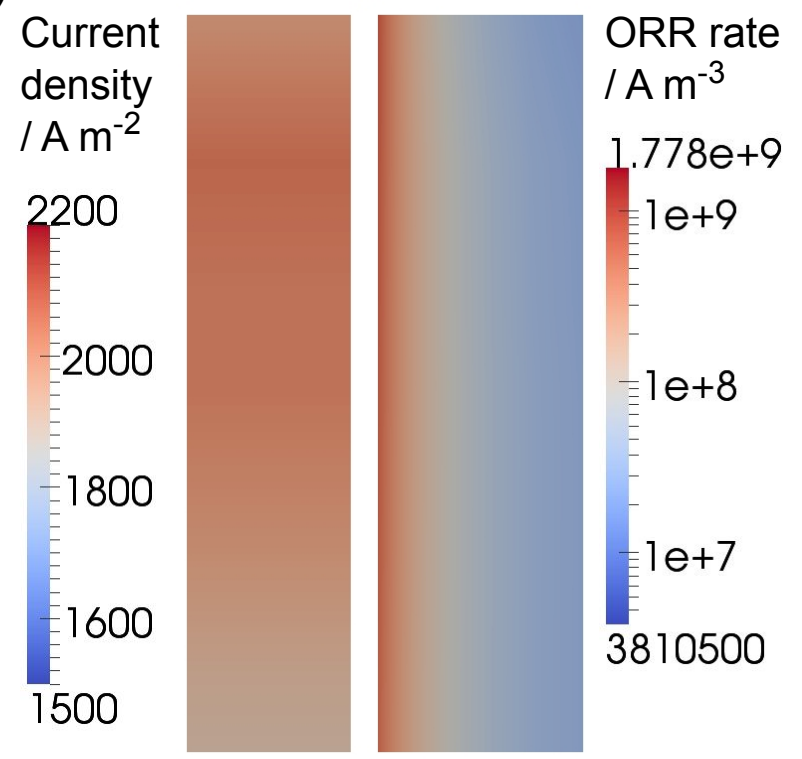

Figure 3: Simulated current density distribution along the channel in the PEM (left) and ORR reaction rate in the CCL (right) in co-flow mode at $2000 \mathrm{~A} \mathrm{~m}^{-2}$. The gas inlets are located at the top. a) $30 \%$ relative humidity, b) $90 \%$ relative humidity. Not drawn to scale. 

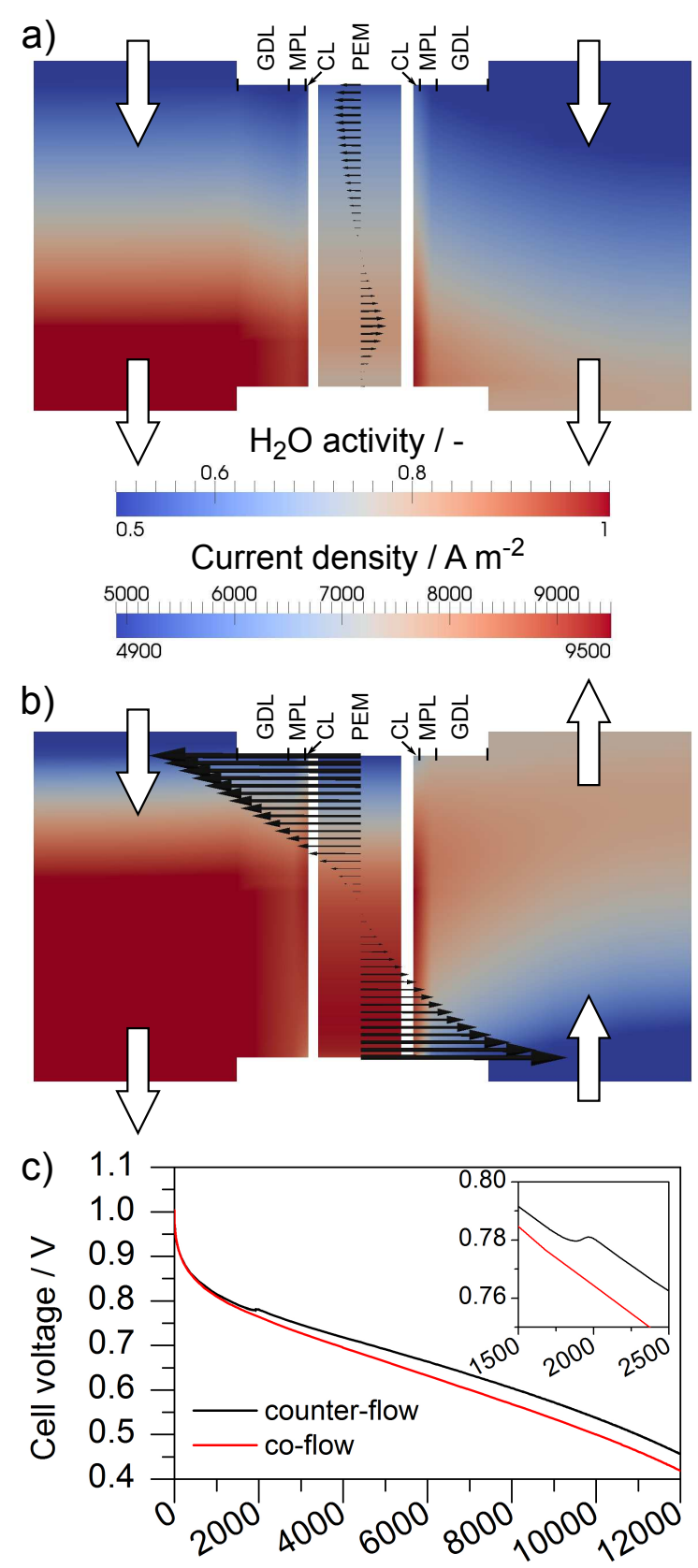

Current density / $\mathrm{A} \mathrm{m}^{-2}$

Figure 4: Simulated distribution of the water activity in the anode (left) and cathode (right) domain at $0.6 \mathrm{~V}, 50 \%$ relative humidity and $353.15 \mathrm{~K}$. Center: simulated current density distribution in the PEM domain. Black arrows indicate orientation and magnitude of the water flux density. White arrows indicate the flow direction in the gas channels. a) co-flow mode, b) counter-flow mode. Not drawn to sç(e. c) Simulated polarization curves in co- and counter-flow mode at $50 \%$ relative humidity and $353.15 \mathrm{~K}$. 
density and therefore the electro-osmotic drag increases due to improved humidification and the water activity in the anode gas stream rises due to hydrogen consumption and humidification from the cathode side. Thus, the direction of water cross-over is reversed towards the anode outlet. It should be noted that the trends strongly depend on the cell current density.

The polarization curve corresponding to counter-flow mode exhibits a small local maximum close to $2000 \mathrm{~A} \mathrm{~m}^{-2}$ which is resolved in the inset. This increase in performance is due to water formation in the anode side of the cell and the lambda control strategy steering the flow rates into the cell. Below $2000 \mathrm{~A}$ $\mathrm{m}^{-2}$, the cell is operated with constant flow rates corresponding to stoichiometric operation at $2000 \mathrm{~A} \mathrm{~m}^{-2}$. Since the lambda-control parameter for $\mathrm{H}_{2}$ is 1.5 in the simulated condition, two thirds of the hydrogen fed to the cell are consumed in the HOR. Therefore, the partial pressure of hydrogen will decrease significantly along the channel, while the partial pressure of water will rise. When the water partial pressure reaches the saturation vapor pressure, a liquid phase will be formed and water activity is equal to unity. This increase in humidification leads to higher performance up to a current density of $\sim 1950 \mathrm{~A} \mathrm{~m}^{-2}$. Above this current density, mass transport limitation again reduces the performance.

The simulated distribution of the liquid phase saturation in the anode and cathode at $50 \%$ and $90 \%$ relative humidity and $12000 \mathrm{~A} \mathrm{~m}^{-2}$ for co- and counter flow operation is depicted in Fig. 5. In the anode, liquid water formation is observed near the outlet in all cases, for the reasons stated above. At $50 \%$ relative humidity (Fig. 5 a) and b)), higher humidification in counter-flow mode is observed, leading to higher saturation of the liquid phase. The location of the two-phase region in the cathode differs significantly for co- and counter-flow. While co-flow operation leads to liquid phase formation near the CL/PEM interface close to the cathode outlet, counter-flow operation results in preferred liquid phase formation in the middle along the channel. At high relative humidity (Fig. 5 c) and d)), the distribution of liquid in the cathode exhibits similar trends along the flow direction for co- and counter-flow. While no liquid phase is present in the GDL near the inlet, a low liquid saturation is predicted towards 
the outlet. Liquid water appears mainly in the CCL and the cathode MPL. A jump of the saturation is predicted at the interface between CL and MPL. Since the liquid phase pressure satisfies mechanical equilibrium at this interface, a change of the capillary-pressure-saturation-relation across the interface results in this jump. The maximum saturation is predicted to be close to $\sim 10$ $\%$ at the PEM/CL interface in both cases. Thus, the influence of flooding on the cell performance is minor even in wet conditions. This finding matches the experimental observations presented in Fig. 2.

\subsection{Impedance analysis}

For further model validation, simulated impedance spectra are compared to the experiments. With the EIS simulation methodology applied in this work, it is possible to resolve all relevant frequencies of the impedance spectra, while the frequency range of the measurements is limited. Therefore, experimentally inaccessible features can be resolved by the simulations. The Bode and Nyquist plots for $30 \%$ and $50 \%$ relative humidity at $2000 \mathrm{~A} \mathrm{~m}^{-2}$ are depicted in Fig. 6 .

Theoretically, the slope of the polarization curve and the real part of the impedance at low frequencies (Fig. 6 a)) are the same. In the EIS, model and experiment show significant deviations in this value even though good agreement between the measured and simulated polarization curves is achieved in these operating points (see Fig. 2). This indicates the presence of inductive phenomena at low frequencies as obtained from the simulations (Fig. 6 b)).

Comparison between experiment and simulation shows that the main features and the corresponding frequencies are reproduced by the model but also reveals significant deviations in the absolute values of the peaks. In particular, the capacitive peak at $\sim 1 \mathrm{~Hz}$ is underestimated by the present model.

In order to understand the origin of the deviations, a deeper understanding of the underlying mechanisms leading to the EIS features is required. Therefore, a systematic analysis was performed elucidating the mechanisms contributing to the overall impedance. For this purpose, impedance simulations were performed with specific model features switched off or modified. For the sake of comparison, 
a)

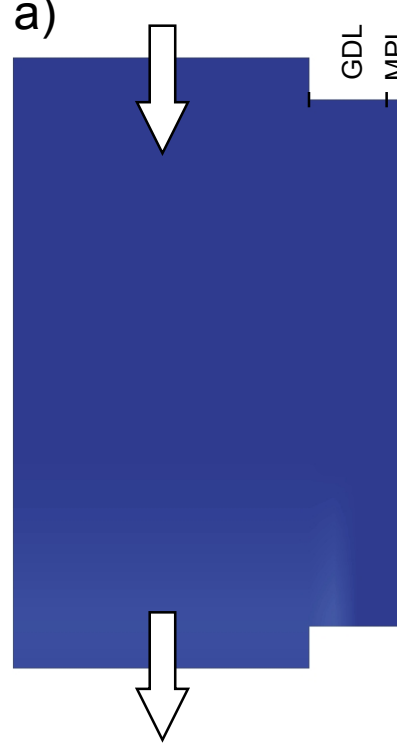

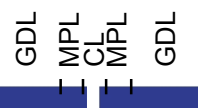

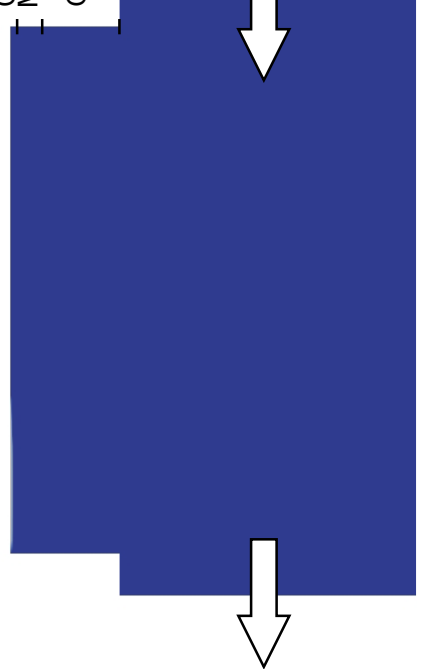

Liquid

b)
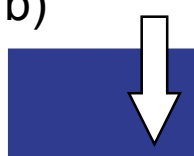

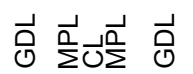
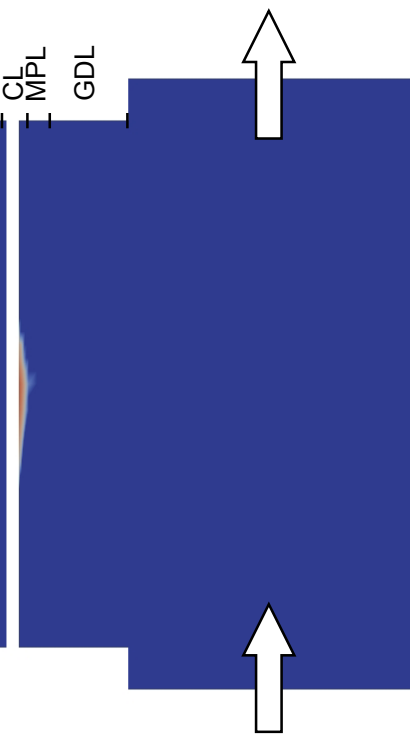

0.025

0.05

0.075

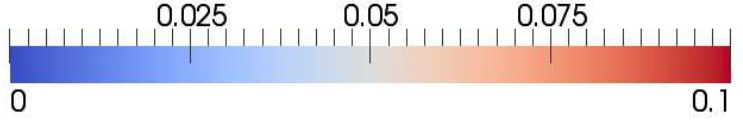

c)

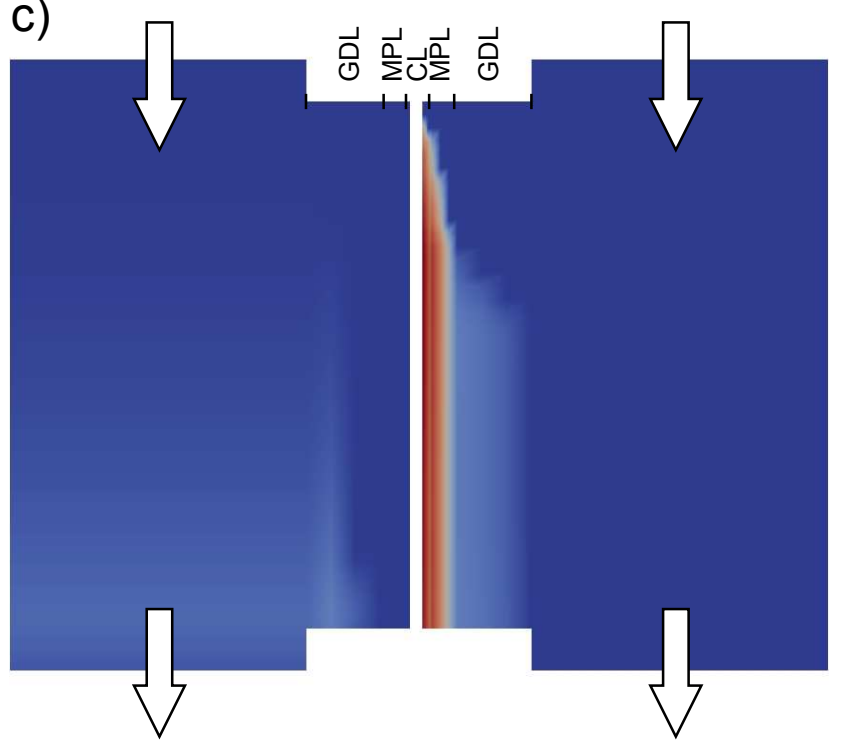

d)

0.1

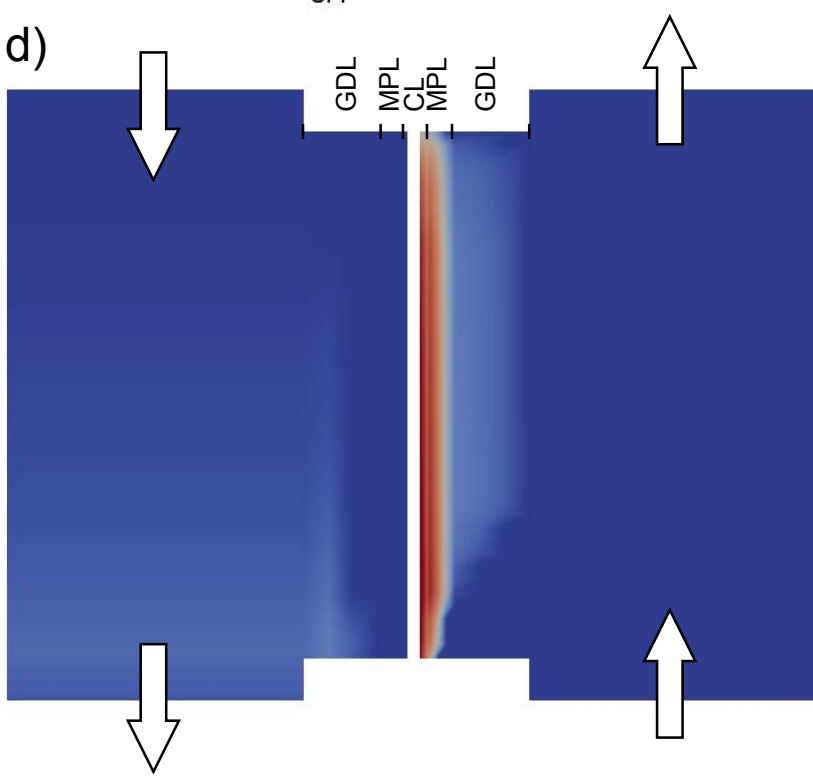

Figure 5: Simulated distribution of the liquid phase saturation in the anode (left) and cathode domain (right) at $12000 \mathrm{~A} \mathrm{~m}^{-2}$ and $353.15 \mathrm{~K}$. a) $50 \%$ relative humidity and co-flow, b) $50 \%$ relative humidity and counter-flow, c) $90 \%$ relative humidity and co-flow, d) $90 \%$ relative humidity and counter-flow. White arrows indicate the flow direction in the gas channels. Not drawn to scale. 

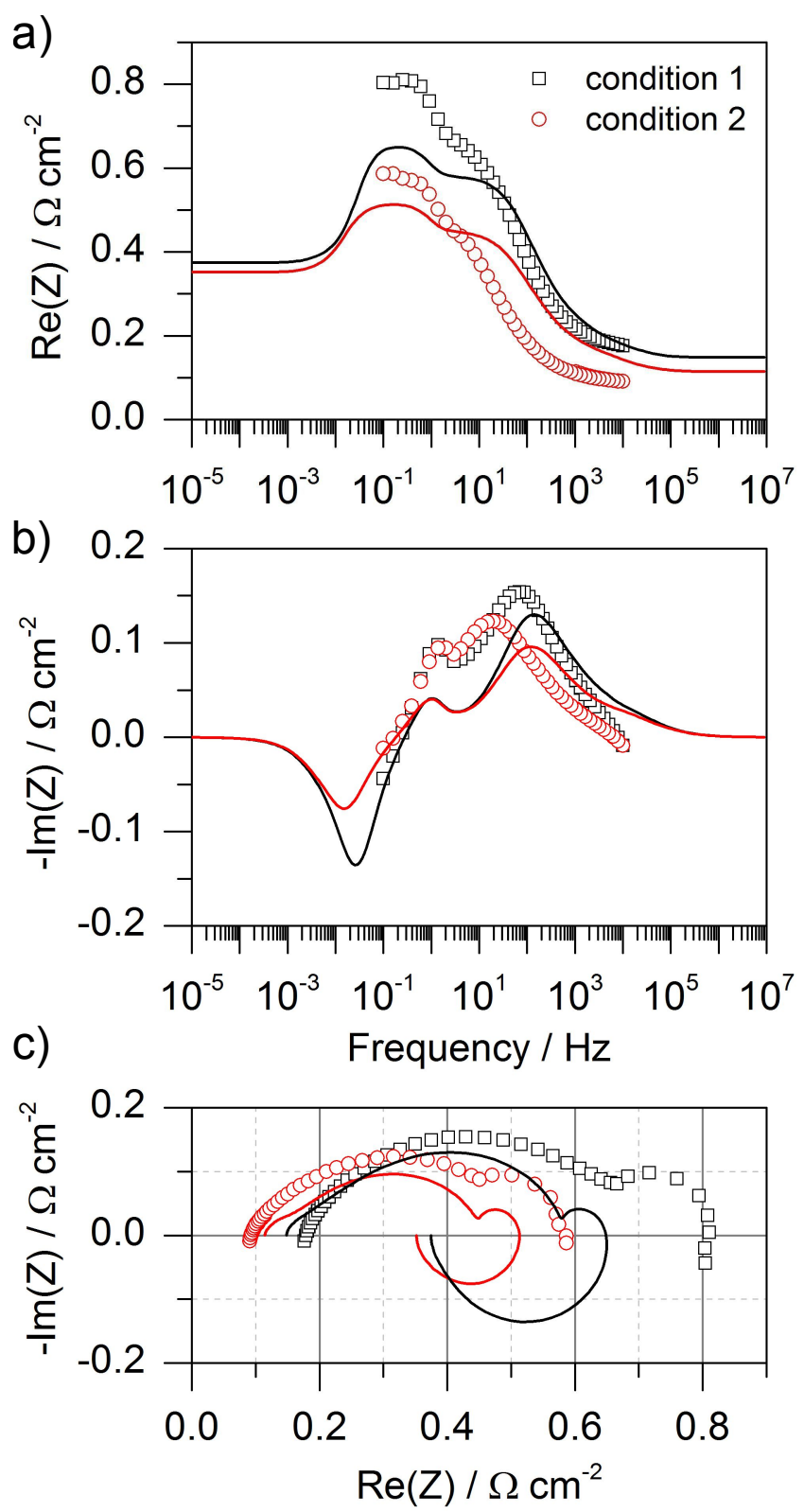

Figure 6: Experimental and simulated impedance spectra at $2000 \mathrm{~A} \mathrm{~m}^{-2}, 30 \%$ and $50 \%$ relative humidity. a) Bode plot of the real part, b) Bode plot of the imaginary part, c) Nyquist plot. 
all simulations where carried out at $30 \%$ relative humidity and $2000 \mathrm{~A} \mathrm{~m}^{-2}$. The simulation results were then compared to the EIS corresponding to condition 1 in Fig. 6.

In Fig. 7 a), the influence of the electrochemical reactions on the impedance spectrum is investigated. To observe the influence of the HOR and ORR, the storage terms of the charge balances (Eq. (22)) are set to zero at the anode or cathode side respectively. The influence of the platinum oxide model is erased from the spectrum by switching off the corresponding reaction. It can be observed that the capacitive peak at $\sim 100 \mathrm{~Hz}$ is mainly caused by the ORR. The contribution of the HOR is minor and manifests itself at $\sim 10^{4} \mathrm{~Hz}$. Without platinum oxide formation, the $100 \mathrm{~Hz}$ peak is slightly decreased, since platinum oxides are considered as site blockers for the ORR. Further, the inductive peak at $\sim 10^{-2} \mathrm{~Hz}$ becomes slightly smaller which is due to the reduction of platinum oxides at lower potentials. When platinum oxides are reduced, the active area available for the ORR will increase, causing an inductive effect.

The influence of mass transport mechanisms is depicted in Fig. 7 b). The influence of diffusion on the simulated impedance is investigated by two simulations: one with fast diffusion, where all diffusion coefficients are multiplied with a factor of 100 , and one where Knudsen diffusion is neglected. Both effects are minor. Therefore, it is concluded that the capacitive peak at $\sim 1 \mathrm{~Hz}$ cannot be caused by diffusion resistances inside the cell. With faster diffusion, the transport of water from the CLs is accelerated. Therefore, the ionomer humidification is slightly reduced leading to a slight increase in the $100 \mathrm{~Hz}$ peak as oxygen transport resistance in the CLs increases. Also a shift to higher frequencies can be observed for the inductive phenomena which will be discussed below.

To eliminate the contribution of concentration gradients along the channel, the model is reduced to pseudo 1D. The height of the gas channels is reduced to $2 \times 10^{-6} \mathrm{~m}$ and, along the channel, Dirichlet conditions corresponding to the inlet conditions are set. Further, the pressure is set to the outlet value here. This way, transport proceeds exclusively in the through plane direction of the 

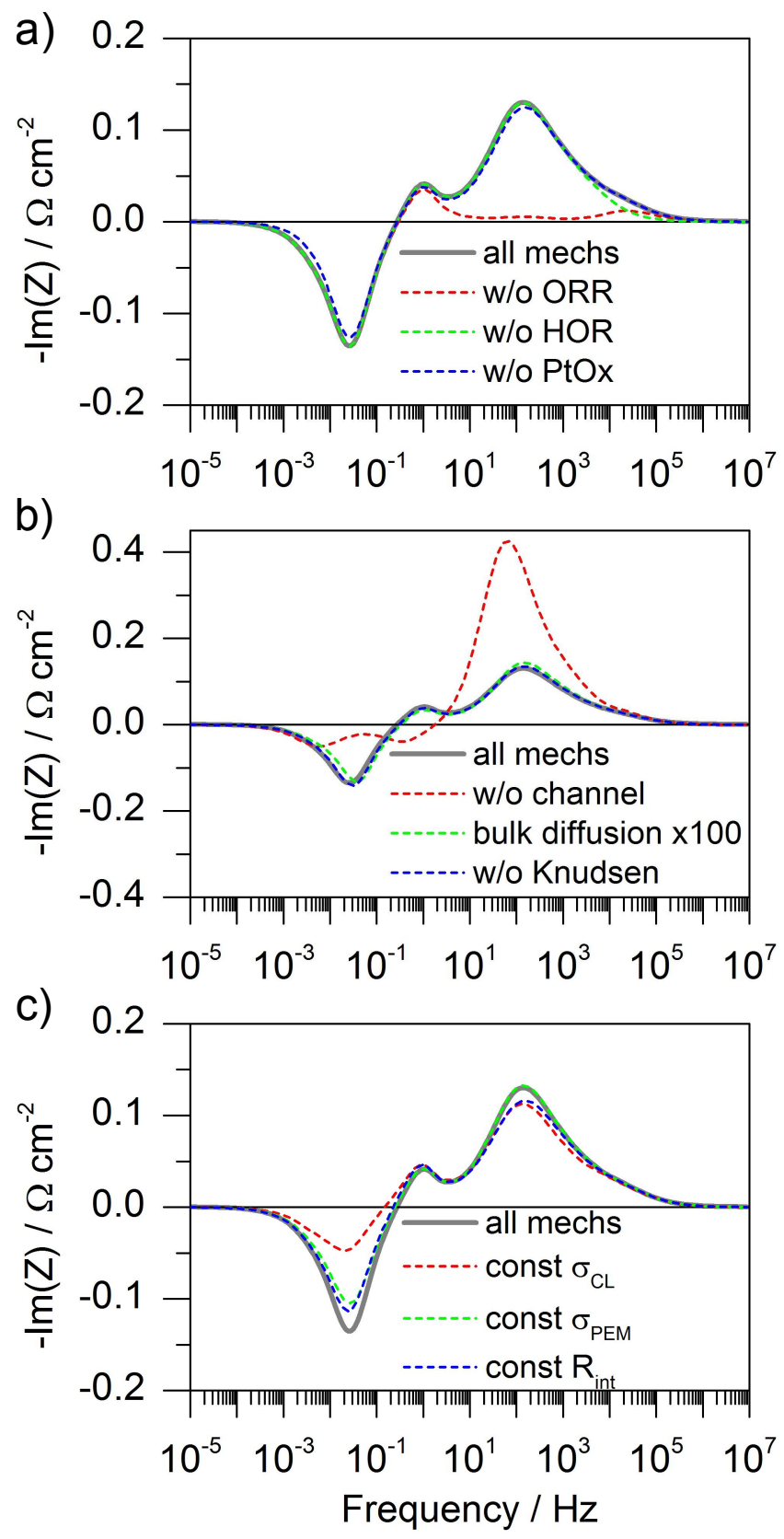

Figure 7: Analysis of a simulated impedance spectrum. Contributions of a) electrochemical reactions, b) mass transport, c) the ionomer. 
GDLs, MPLs, CLs and the PEM. Comparison of the simulation without channel transport and the reference simulation (Fig. 7 b)) reveals a huge increase of the $\sim 100 \mathrm{~Hz}$ peak in the 'no channel' setup. This effect is caused by reduced humidification since, in this case, water cannot accumulate along the channel and the dry inlet conditions govern the cell performance. The capacitive peak at $\sim 1 \mathrm{~Hz}$ vanishes in this setup. This demonstrates that this feature is mainly caused by the concentration gradients along the channel. Again, the frequencies of some inductive mechanisms are increased from $\sim 10^{-2} \mathrm{~Hz}$ to $\sim 3 \times 10^{-1} \mathrm{~Hz}$ in this simulation, revealing two distinct inductive mechanisms.

The influence of the ionomer properties on the impedance is investigated in Fig. 7 c). For these simulations, the relations for the ionomer properties were replaced by constant values, independent of the local relative humidity. Simulations with a constant ionic conductivity of the PEM (Eq. (5)), $\sigma_{i o n, P E M}=3.4 \mathrm{~S}$ $\mathrm{m}^{-1}$, a constant ionic conductivity of the CL ionomer (Eq. (26)), $\sigma_{i o n, C L}=0.045$ $\mathrm{S} \mathrm{m}^{-1}$, and a constant interfacial oxygen transport resistance at the ionomer films (Eq. (49)), $R_{\text {int }}=4.5 \times 10^{3}$, were carried out. All simulations show a significant reduction of the inductive peak, most pronounced for the simulation with constant ionic conductivity of the CLs. It becomes clear that ionomer properties, depending on relative humidity, result in inductive phenomena at low frequencies. The explanation is straight forward: with increasing current density, more water is produced in the ORR. Water transport through the membrane and along the channel is slow which corresponds to a low frequency processes. With increasing relative humidity, the ohmic resistance is reduced, oxygen transport to the catalyst increases and the effective catalyst utilization is improved (see Fig. 3).

The change of CL ionic conductivity with water activity is most pronounced under dry conditions (see Eq. (26)). Therefore induction is strong in this case (see Fig. $7 \mathrm{c}$ )). With increasing humidity, the same effects, while less pronounced, are still operative and significant. In Fig. 6 b), the EIS at $50 \%$ relative humidity is depicted along with the dry condition. In this case, induction also has a strong effect on the performance. With increasing current density and 
humidification, the inductive effects become smaller.

With the analysis presented above, new light is shed on the deviations between the experimental data and and the simulations shown in Fig. 6. The most significant deviation is observed in the capacitive peak close to $1 \mathrm{~Hz}$. Since this peak corresponds to concentration gradients along the gas channel, one shortcoming of the present model is revealed: its simplified 2D geometry.

In Fig. 8, an experimentally measured current density distribution of the cell is depicted. In Fig. 8 a), a sketch of the single serpentine flow field is added. Along the channel, the cell performance increases until flooding close to the outlet leads to reduction of the cell performance. In Fig. 8 b), the same distribution is shown in a $3 \mathrm{D}$ plot. Here, it is obvious that the current density distribution close to the gas channel bends experiences a significant drop. This effect cannot be captured by a straight 2D- or even 3D channel model and therefore, concentration gradients are underestimated, which explains the deviations between simulation and experiment.

\section{Conclusions}

A new numerical framework for the simulation of energy conversion devices called NEOPARD-X has been established and a detailed PEMFC model has been incorporated into the framework. The model has been validated under various operating conditions using a single set of parameters.

Since the ionic conductivity of ionomer thin-films in the CLs is low under dry conditions, good humidification is of paramount importance in order to ensure high cell performance. Close to the gas inlets, ionomer dehydration severely reduces the effective catalyst utilization when the cell is operated with dry gases.

Excessive increase of the gas flow rates leads to reduced humidification of the ionomer. This will outweigh the elevated reactant concentrations inside the cell and the overall cell performance is reduced.

Capturing the effect of humidification on the fuel cell performance is impos- 
a)
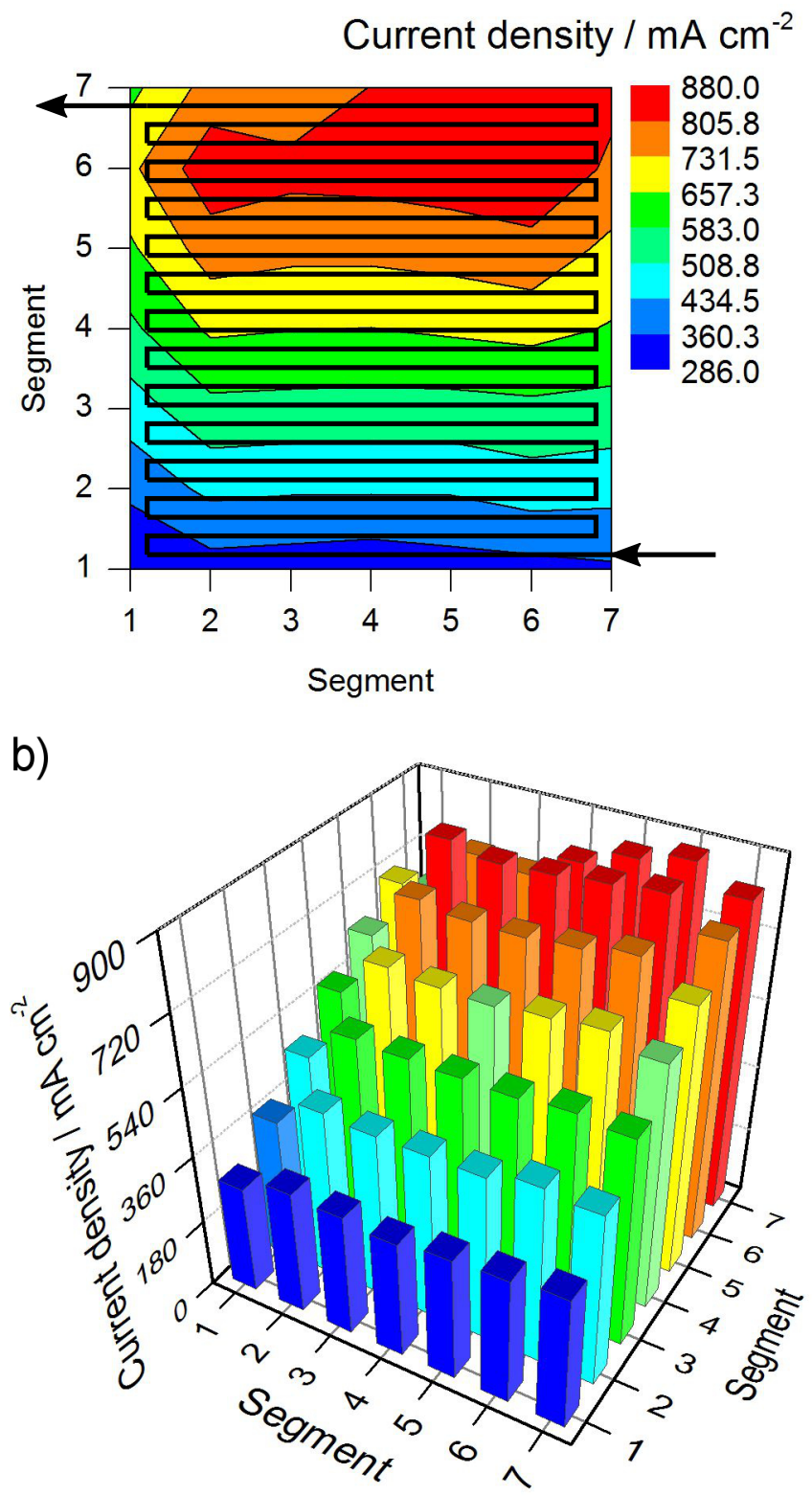

Figure 8: Segmented measurement of the current density distribution at $6000 \mathrm{~A} \mathrm{~m}^{-2}, 30 \%$ relative humidity and $353.15 \mathrm{~K}$. a) with sketch of the flow field, b) 3D for better visualization of the performance drop at the borders. 
sible without spatial resolution of the CLs since strong potential gradients and variations of the local reaction rates may exist in these layers. This effect is most pronounced for operation at low relative humidity.

To understand the water management in the cell, the local exchange of water between cathode and anode needs to be considered. In co-flow mode, the water generated in the ORR humidifies the anode inlet. Close to the outlet this trend is reversed and water is transported from the anode to the cathode. This effect is caused by hydrogen depletion along the anode channel leading to an increase in water partial pressure. In counter-flow mode, this water cycle is greatly enhanced since the water concentration gradients between anode and cathode side of the cell are stronger and the cell performance increases. Flooding of the cathode appears at high current densities close to the gas channel outlets for co-flow operation, or in the center along the channel in counter-flow mode.

The physical mechanisms contributing to the cell impedance have been analyzed in detail. High frequency capacitive features are caused by the electrochemical half-cell reactions. At lower frequencies, concentration gradients along the channel manifest themselves causing capacitive behavior. The influence of diffusion through the porous electrodes on the impedance is minor. The main mechanisms leading to inductive phenomena at low frequencies are identified from physics-based simulations. Increased humidification leads to improved ionic conductivity as well as reduced oxygen transport resistance of the ionomer thin-films. Therefore, water generation due to the ORR and its slow distribution inside the cell cause induction. Further, the reduction of platinum oxides causes inductive behavior.

In the present state, the model is capable to qualitatively match the experimental EIS, while quantitative agreement between measured and simulated polarization curves is achieved. This further indicates that strong inductive phenomena must be operative in order to obtain the experimental polarization curve. The observed discrepancy between model and experiment arises from the simplified model geometry which does not account for three-dimensional heterogeneities causing stronger reactant concentration gradients inside the fuel 
cell.

\section{Acknowledgments}

We thank the Dumux developers at the IWS - Department of Hydromechanics and Modelling of Hydrosystems, University of Stuttgart, for their excellent work and kind support. Further, we thank EWii Fuel Cell for providing the MEAs. The research leading to these results has received funding from the European Union's Seventh Framework Program (FP7/2007-2013) for the Fuel Cells and Hydrogen Joint Technology Initiative under grant agreement $\mathrm{n}^{\circ} .303419$ and $n^{\circ} 621216$.

\section{Nomenclature}

\begin{tabular}{|c|c|}
\hline \multicolumn{2}{|c|}{$\underline{\text { Roman symbols }}$} \\
\hline$\alpha^{\kappa}$ & activity of species $\kappa$ \\
\hline$A$ & area $/ \mathrm{m}^{2}$ \\
\hline$c^{\kappa}$ & concentration of species $\kappa / \mathrm{mol} \mathrm{m}^{-3}$ \\
\hline$c_{p}$ & isobaric heat capacity / $\mathrm{J} \mathrm{kg}^{-1} \mathrm{~K}^{-1}$ \\
\hline$C_{D L}$ & double layer capacitance / $\mathrm{F} \mathrm{m}^{-3}$ \\
\hline $\mathbf{d}_{\alpha}^{\kappa}$ & diffusive flux density of species $\kappa$ in phase $\alpha / \mathrm{mol} \mathrm{m}^{-2} \mathrm{~s}^{-1}$ \\
\hline$D$ & diffusion coefficient $/ \mathrm{m}^{2} \mathrm{~s}^{-1}$ \\
\hline$E^{0}$ & equilibrium voltage / V \\
\hline$E_{\text {act }}$ & activation energy / $\mathrm{J} \mathrm{mol}^{-1}$ \\
\hline$E C S A$ & electrochemically active surface area $/ \mathrm{m}^{2} \mathrm{~m}^{-3}$ \\
\hline$E W$ & equivalent weight $/ \mathrm{kg} \mathrm{mol}^{-1}$ \\
\hline$h^{\kappa}$ & molar enthalpy of species $\kappa / \mathrm{J} \mathrm{mol}^{-1}$ \\
\hline $\mathrm{i}$ & current density / $\mathrm{A} \mathrm{m}^{2}$ \\
\hline$i^{0}$ & exchange current density / $\mathrm{A} \mathrm{m}^{2}$ \\
\hline$I$ & current / A \\
\hline$k^{i}$ & rate constant of reaction $i /$ various \\
\hline
\end{tabular}




\begin{tabular}{|c|c|}
\hline$k_{r, \alpha}$ & relative permeability of phase $\alpha$ \\
\hline $\mathbf{K}$ & intrinsic permeability/ $\mathrm{m}^{2}$ \\
\hline$M^{\kappa}$ & molar mass of species $\kappa / \mathrm{kg} \mathrm{mol}^{-1}$ \\
\hline $\mathbf{n}$ & normal vector \\
\hline$n_{d r a g}$ & electro-osmotic drag coefficient \\
\hline$p^{\kappa}$ & partial pressure of species $\kappa / \mathrm{Pa}$ \\
\hline$p_{\alpha}$ & pressure of phase $\alpha / \mathrm{Pa}$ \\
\hline$q^{\kappa}$ & source/sink term of species $\kappa /$ various \\
\hline$r^{i}$ & volumetric reaction rate of reaction $i / \mathrm{A} \mathrm{m}^{-3}$ \\
\hline$R$ & resistance / $\mathrm{s} \mathrm{m}^{-1}$ \\
\hline$\Delta s^{i}$ & reaction entropy of reaction $i / \mathrm{J} \mathrm{mol}^{-1} \mathrm{~K}^{-1}$ \\
\hline$S_{\alpha}$ & saturation of phase $\alpha$ \\
\hline$S_{c h}$ & fraction of expanded channels \\
\hline$t$ & time / s \\
\hline$T$ & temperature / K \\
\hline$u_{\alpha}$ & internal energy of phase $\alpha / \mathrm{J} \mathrm{kg}^{-1}$ \\
\hline$v^{\kappa}$ & partial molar volume of species $\kappa / \mathrm{m}^{3} \mathrm{~mol}^{-1}$ \\
\hline $\mathbf{v}_{\alpha}$ & velocity of phase $\alpha / \mathrm{m} \mathrm{s}^{-1}$ \\
\hline$x_{\alpha}^{\kappa}$ & mole fraction of species $\kappa$ in phase $\alpha$ \\
\hline \multicolumn{2}{|l|}{ Greek symbols } \\
\hline$\alpha^{f, r}$ & transfer coefficient of the forward/reverse reaction \\
\hline$\alpha$ & transport coefficient $/ \mathrm{mol}^{2} \mathrm{~J}^{-1} \mathrm{~m}^{-1} \mathrm{~s}^{-1}$ \\
\hline$\eta^{i}$ & overpotential of reaction $i / \mathrm{V}$ \\
\hline$\lambda$ & heat conductivity / $\mathrm{W} \mathrm{m} \mathrm{m}^{-1} \mathrm{~K}^{-1}$ \\
\hline$\lambda^{\kappa}$ & moles of species $\kappa$ per sulfonic acid group \\
\hline$\lambda^{f l u x, \kappa}$ & lambda-control parameter of species $\kappa$ \\
\hline$\mu^{\kappa}$ & chemical potential of species $\kappa$ \\
\hline$\mu_{\alpha}$ & dynamic viscosity of phase $\alpha$ \\
\hline$\phi$ & volume fraction or porosity \\
\hline
\end{tabular}




$\begin{array}{ll}\Phi & \text { potential / V } \\ \Pi^{i} & \text { Peltier coefficient of reaction } i / \mathrm{V} \\ \Psi^{\kappa} & \text { flux term of species } \kappa / \text { various } \\ \psi^{\kappa} & \text { permeation coefficient of species } \kappa / \mathrm{mol} \mathrm{s}^{-1} \mathrm{~m}^{-1} \\ \rho & \text { mass density } / \mathrm{kg} \mathrm{m}^{-3} \\ \rho_{m o l} & \text { molar density } / \mathrm{mol} \mathrm{m}^{-3} \\ \sigma & \text { conductivity } / \mathrm{S} \mathrm{m}^{-1} \\ \sigma^{\text {surface }} & \text { surface tension } / \mathrm{N} \mathrm{m}^{-1} \\ \theta & \text { contact angle / } ~ \\ \theta^{\kappa} & \text { surface coverage of species } \kappa \\ v^{\kappa} & \text { stoichiometry coefficient of species } \kappa \\ \xi^{\kappa} & \text { storage term of species } \kappa / \text { various }\end{array}$

\section{References}

[1] T. Jahnke, G. Futter, A. Latz, T. Malkow, G. Papakonstantinou, G. Tsotridis, P. Schott, M. Gérard, M. Quinaud, M. Quiroga, A. A. Franco, K. Malek, F. Calle-Vallejo, R. Ferreira De Morais, T. Kerber, P. Sautet, D. Loffreda, S. Strahl, M. Serra, P. Polverino, C. Pianese, M. Mayur, W. G. Bessler, C. Kompis, Performance and degradation of Proton Exchange Membrane Fuel Cells: State of the art in modeling from atomistic to system scale, Journal of Power Sources 304 (2016) 207-233. doi:10.1016/j.jpowsour.2015.11.041.

[2] A. Z. Weber, R. L. Borup, R. M. Darling, P. K. Das, T. J. Dursch, W. Gu, D. Harvey, A. Kusoglu, S. Litster, M. M. Mench, R. Mukundan, J. P. Owejan, J. G. Pharoah, M. Secanell, I. V. Zenyuk, A Critical Review of Modeling Transport Phenomena in Polymer-Electrolyte Fuel Cells, Journal of the Electrochemical Society 161 (12) (2014) F1254-F1299. doi:10.1149/2.0751412jes.

[3] C. Vallieres, D. Winkelmann, D. Roizard, E. Favre, P. Scharfer, M. Kind, 
On Schroeder's paradox, Journal of Membrane Science 278 (1-2) (2006) 357-364. doi:10.1016/j.memsci.2005.11.020.

[4] K.-D. Kreuer, The role of internal pressure for the hydration and transport properties of ionomers and polyelectrolytes, Solid State Ionics 252 (2013) 93-101. doi:10.1016/j.ssi.2013.04.018.

[5] S. Ge, X. Li, B. Yi, I.-M. Hsing, Absorption, Desorption, and Transport of Water in Polymer Electrolyte Membranes for Fuel Cells, Journal of The Electrochemical Society 152 (6) (2005) A1149-A1157. doi:10.1149/1.1899263.

[6] D. T. Hallinan, M. G. De Angelis, M. Giacinti Baschetti, G. C. Sarti, Y. A. Elabd, Non-Fickian Diffusion of Water in Nafion, Macromolecules 43 (10) (2010) 4667-4678. doi:10.1021/ma100047z.

[7] T. J. Silverman, J. P. Meyers, J. J. Beaman, Modeling Water Transport and Swelling in Polymer Electrolyte Membranes, Journal of The Electrochemical Society 157 (10) (2010) B1376-B1381. doi:10.1149/1.3464805.

[8] T. J. Silverman, J. P. Meyers, J. J. Beaman, Dynamic thermal, transport and mechanical model of fuel cell membrane swelling, Fuel Cells 11 (6) (2011) 875-887. doi:10.1002/fuce.201100025.

[9] Q. He, A. Kusoglu, I. T. Lucas, K. Clark, A. Z. Weber, R. Kostecki, Correlating humidity-dependent ionically conductive surface area with transport phenomena in proton-exchange membranes, Journal of Physical Chemistry B 115 (40) (2011) 11650-11657. doi:10.1021/jp206154y.

[10] T. E. Springer, T. A. Zawodzinski, S. Gottesfeld, Polymer Electrolyte Fuel Cell Model, J. Electrochem. Soc. 138 (8) (1991) 2334-2342. doi:10.1149/1.2085971.

[11] D. M. Bernardi, M. W. Verbrugge, Mathematical model of a gas diffusion electrode bonded to a polymer electrolyte, AIChE Journal 37 (8) (1991) 1151-1163. doi:10.1002/aic.690370805. 
[12] D. M. Bernardi, M. W. Verbrugge, A Mathematical Model of the SolidPolymer-Electrolyte Fuel Cell, J. Electrochem. Soc. 139 (9) (1992) 24772491. doi:10.1149/1.2221251.

[13] M. Eikerling, Phenomenological Theory of Electro-osmotic Effect and Water Management in Polymer Electrolyte Proton-Conducting Membranes, Journal of The Electrochemical Society 145 (8) (1998) 2684-2699. doi:10.1149/1.1838700.

[14] T. F. Fuller, J. Newman, Water and Thermal Management in SolidPolymer-Electrolyte Fuel Cells, J. Electrochem. Soc. 140 (5) (1993) 12181225. doi:10.1149/1.2220960.

[15] G. J. M. Janssen, A Phenomenological Model of Water Transport in a Proton Exchange Membrane Fuel Cell, Journal of The Electrochemical Society 148 (12) (2001) A1313-A1323. doi:10.1149/1.1415031.

[16] A. Z. Weber, J. Newman, Transport in Polymer-Electrolyte Membranes II. Mathematical Model, Journal of The Electrochemical Society 151 (2) (2004) A311-A325. doi:10.1149/1.1639157.

[17] A. Parthasarathy, C. R. Martin, S. Srinivasan, Investigations of the $\mathrm{O}_{2}$ Reduction Reaction at the Platinum/Nafion ${ }^{\circledR}$ Interface Using a Solid-State Electrochemical Cell, Journal of The Electrochemical Society 138 (4) (1991) 916-921. doi:10.1149/1.2085747.

[18] A. Parthasarathy, B. Davé, S. Srinivasan, A. J. Appleby, C. R. Martin, The Platinum Microelectrode/Nafion Interface: An Electrochemical Impedance Spectroscopic Analysis of Oxygen Reduction Kinetics and Nation Characteristics, Journal of The Electrochemical Society 139 (6) (1992) 1634-1641. doi:10.1149/1.2069469.

[19] A. Parthasarathy, Pressure Dependence of the Oxygen Reduction Reaction at the Platinum Microelectrode/Nafion Interface: Electrode Kinetics and 
Mass Transport, Journal of The Electrochemical Society 139 (10) (1992) 2856-2862. doi:10.1149/1.2068992.

[20] A. Parthasarathy, S. Srinivasan, A. J. Appleby, C. R. Martin, Temperature dependence of the electrode kinetics of oxygen reduction at the platinum/Nafion interface - A microelectrode investigation, Journal of The Electrochemical Society 139 (9) (1992) 2530-2537. doi:10.1149/1.2221258.

[21] W. Sun, B. A. Peppley, K. Karan, An improved two-dimensional agglomerate cathode model to study the influence of catalyst layer structural parameters, Electrochimica Acta 50 (16-17) (2005) 3359-3374. doi:10.1016/j.electacta.2004.12.009.

[22] D. Harvey, J. G. Pharoah, K. Karan, A comparison of different approaches to modelling the PEMFC catalyst layer, Journal of Power Sources 179 (1) (2008) 209-219. doi:10.1016/j.jpowsour.2007.12.077.

[23] J. X. Wang, J. Zhang, R. R. Adzic, Double-Trap Kinetic Equation for the Oxygen Reduction Reaction on Pt(111) in Acidic Media, Journal of Physical Chemistry A 111 (2007) 12702-12710. doi:10.1021/jp076104e.

[24] J. X. Wang, F. A. Uribe, T. E. Springer, J. Zhang, R. R. Adzic, Intrinsic kinetic equation for oxygen reduction reaction in acidic media: the double Tafel slope and fuel cell applications, Faraday Discuss. 140 (2008) 347-362. doi:10.1039/B814058H.

[25] M. Moore, A. Putz, M. Secanell, Investigation of the ORR Using the Double-Trap Intrinsic Kinetic Model, Journal of the Electrochemical Society 160 (6) (2013) F670-F681. doi:10.1149/2.123306jes.

[26] M. Markiewicz, C. Zalitis, A. Kucernak, Performance measurements and modelling of the ORR on fuel cell electrocatalysts - The modified double trap model, Electrochimica Acta 179 (2015) 126-136. doi:10.1016/j.electacta.2015.04.066. 
[27] K. Kudo, R. Jinnouchi, Y. Morimoto, Humidity and Temperature Dependences of Oxygen Transport Resistance of Nafion Thin Film on Platinum Electrode, Electrochimica Acta 209 (2016) 682-690. doi:10.1016/j.electacta.2016.04.023.

[28] J. P. Owejan, J. E. Owejan, W. Gu, Impact of Platinum Loading and Catalyst Layer Structure on PEMFC Performance, Journal of the Electrochemical Society 160 (8) (2013) F824-F833. doi:10.1149/2.072308jes.

[29] H. Liu, W. K. Epting, S. Litster, Gas Transport Resistance in Polymer Electrolyte Thin Films on Oxygen Reduction Reaction Catalysts, Langmuir 31 (36) (2015) 9853-9858. doi:10.1021/acs.langmuir.5b02487.

[30] A. A. Shah, T. R. Ralph, F. C. Walsh, Modeling and Simulation of the Degradation of Perfluorinated Ion-Exchange Membranes in PEM Fuel Cells, Journal of The Electrochemical Society 156 (4) (2009) B465-B484. doi:10.1149/1.3077573.

[31] F. C. Cetinbas, S. G. Advani, A. K. Prasad, An Improved Agglomerate Model for the PEM Catalyst Layer with Accurate Effective Surface Area Calculation Based on the Sphere-Packing Approach, Journal of the Electrochemical Society 161 (6) (2014) F803-F813. doi:10.1149/2.116406jes.

[32] M. Moein-Jahromi, M. Kermani, Performance prediction of PEM fuel cell cathode catalyst layer using agglomerate model, International Journal of Hydrogen Energy 37 (23) (2012) 17954-17966. doi:10.1016/j.ijhydene.2012.09.120.

[33] M. Secanell, K. Karan, A. Suleman, N. Djilali, Multi-variable optimization of PEMFC cathodes using an agglomerate model, Electrochimica Acta 52 (22) (2007) 6318-6337. doi:10.1016/j.electacta.2007.04.028.

[34] A. Kulikovsky, How important is oxygen transport in agglomerates in a PEM fuel cell catalyst layer?, Electrochimica Acta 130 (2014) 826-829. doi:10.1016/j.electacta.2014.03.131. 
[35] L. Hao, K. Moriyama, W. Gu, C.-Y. Wang, Modeling and Experimental Validation of Pt Loading and Electrode Composition Effects in PEM Fuel Cells, Journal of the Electrochemical Society 162 (8) (2015) F854-F867. doi:10.1149/2.0221508jes.

[36] M. Acosta, C. Merten, G. Eigenberger, H. Class, R. Helmig, B. Thoben, H. Müller-Steinhagen, Modeling non-isothermal two-phase multicomponent flow in the cathode of PEM fuel cells, Journal of Power Sources 159 (2) (2006) 1123-1141. doi:10.1016/j.jpowsour.2005.12.068.

[37] T. Berning, M. Odgaard, S. K. Kær, A Computational Analysis of Multiphase Flow Through PEMFC Cathode Porous Media Using the Multifluid Approach, Journal of The Electrochemical Society 156 (11) (2009) B1301. doi:10.1149/1.3206691.

URL http://jes.ecsdl.org/content/156/11/B1301.full

[38] T. Berning, M. Odgaard, S. K. Kær, A study of multi-phase flow through the cathode side of an interdigitated flow field using a multifluid model, Journal of Power Sources 195 (15) (2010) 4842-4852. doi:10.1016/j.jpowsour.2010.02.017.

[39] T. Berning, M. Odgaard, S. Kær, Water balance simulations of a polymerelectrolyte membrane fuel cell using a two-fluid model, Journal of Power Sources 196 (15) (2011) 6305-6317. doi:10.1016/j.jpowsour.2011.03.068.

URL http://linkinghub.elsevier.com/retrieve/pii/S0378775311006835

[40] C. Y. Wang, P. Cheng, A multiphase mixture model for multiphase, multicomponent transport in capillary porous media - I. Model development, International Journal of Heat and Mass Transfer 39 (17) (1996) 3607-3618. doi:10.1016/0017-9310(96)00036-1.

[41] F. N. Buchi, S. Srinivasa, Operating Proton Exchange Membrane Fuel Cells Without External Humidification of the Reactant Gases, Journal of The Electrochemical Society 144 (8) (1997) 2767-2772. doi:10.1149/1.1837893. URL http://jes.ecsdl.org/cgi/doi/10.1149/1.1837893 
[42] P. W. Majsztrik, M. B. Satterfield, A. B. Bocarsly, J. B. Benziger, Water sorption, desorption and transport in Nafion membranes, Journal of Membrane Science 301 (1-2) (2007) 93-106. doi:10.1016/j.memsci.2007.06.022.

[43] M. B. Satterfield, J. B. Benziger, Non-Fickian Water Vapor Sorption Dynamics by Nafion Membranes, Journal of Physical Chemistry B 112 (2008) 3693-3704. doi:10.1021/jp7103243.

[44] T. Romero, W. Mérida, Water transport in liquid and vapour equilibrated Nafion membranes, Journal of Membrane Science 338 (1-2) (2009) 135-144. doi:10.1016/j.memsci.2009.04.018.

[45] F. M. White, Fluid Mechanics, 5th Edition, McGraw-Hill, 2002.

[46] R. Helmig, Multiphase Flow and Transport Processes in the Subsurface, Springer-Verlag Berlin Heidelberg, 1997.

[47] J. Newman, K. E. Thomas-Alyea, Electrochemical Systems, 3rd Edition, John Wiley \& Sons, 2004.

[48] J. P. Meyers, J. Newman, Simulation of the Direct Methanol Fuel Cell I. Themodynamic Framework for a Multicomponent Membrane, Journal of The Electrochemical Society 149 (6) (2002) A710-A717. doi:10.1149/1.1473188.

[49] O. Burheim, P. J. S. Vie, J. G. Pharoah, S. Kjelstrup, Ex situ measurements of through-plane thermal conductivities in a polymer electrolyte fuel cell, Journal of Power Sources 195 (1) (2010) 249-256. doi:10.1016/j.jpowsour.2009.06.077.

[50] Y. Bachmat, J. Bear, On the concept and size of a representative elementary volume (rev), in: Advances in Transport Phenomena in Porous Media, Springer Netherlands, 1987, pp. 3-20. doi:10.1007/978-94-009-3625-6.

[51] A. Lauser, C. Hager, R. Helmig, B. Wohlmuth, A new approach for phase transitions in miscible multi-phase flow in porous media, Advances in Water Resources 34 (2011) 957-966. doi:10.1016/j.advwatres.2011.04.021. 
[52] A. E. Scheidegger, The physics of flow through porous media, University of Toronto Press, 1974.

[53] M. C. Leverett, Capillary behavior in porous solids, Transactions of the AIMEdoi:https://doi.org/10.2118/941152-G.

[54] T. Rosén, J. Eller, J. Kang, N. I. Prasianakis, J. Mantzaras, F. N. Büchi, Saturation Dependent Effective Transport Properties of PEFC Gas Diffusion Layers, Journal of the Electrochemical Society 159 (9) (2012) F536F544. doi:10.1149/2.005209jes.

[55] R. B. Bird, W. E. Stewart, E. N. Lightfoot, Transport Phenomena, 2nd Edition, John Wiley \& Sons, 2006.

[56] E. N. Fuller, P. D. Schettler, J. C. Giddings, A New Method for Prediction of Binary Gas-Phase Diffusion, Ind. Eng. Chem 58 (5) (1966) 18-27. doi:10.1021/ie50677a007.

[57] M. Eikerling, Water Management in Cathode Catalyst Layers of PEM Fuel Cells, Journal of The Electrochemical Society 153 (3) (2006) E58-E70. doi:10.1149/1.2160435.

[58] B. P. Setzler, T. F. Fuller, A Physics-Based Impedance Model of Proton Exchange Membrane Fuel Cells Exhibiting Low-Frequency Inductive Loops, Journal of the Electrochemical Society 162 (6) (2015) F519-F530. doi:10.1149/2.0361506jes.

[59] A. Kusoglu, A. Kwong, K. T. Clark, H. P. Gunterman, A. Z. Weber, Water Uptake of Fuel-Cell Catalyst Layers, Journal of the Electrochemical Society 159 (9) (2012) F530-F535. doi:10.1149/2.031209jes.

[60] D. K. Paul, R. McCreery, K. Karan, Proton Transport Property in Supported Nafion Nanothin Films by Electrochemical Impedance Spectroscopy, Journal of the Electrochemical Society 161 (14) (2014) F1395-F1402. doi:10.1149/2.0571414jes. 
[61] W. Somerton, J. Keese, S. Chu, Thermal behavior of unconsolidated oil sands, Society of Petroleum Engineers Journaldoi:10.2118/4506-PA.

[62] IAPWS, Release on the iapws formulation 2011 for the thermal conductivity of ordinary water substance, Tech. rep., IAPWS (2011).

URL http://www.iapws.org/relguide/ThCond.pdf

[63] T. Bednarek, G. Tsotridis, Calculation of effective transport properties of partially saturated gas diffusion layers, Journal of Power Sources 340 (2017) 111-120. doi:10.1016/j.jpowsour.2016.10.098.

[64] M. J. Lampinen, M. Fomino, Analysis of Free Energy and Entropy Changes for Half-Cell Reactions, Journal of The Electrochemical Society 140 (12) (1993) 3537-3546. doi:10.1149/1.2221123.

[65] K. C. Neyerlin, W. Gu, J. Jorne, H. A. Gasteiger, Study of the Exchange Current Density for the Hydrogen Oxidation and Evolution Reactions, Journal of The Electrochemical Society 154 (2007) B631-B635. doi:10.1149/1.2733987.

[66] K. C. Neyerlin, W. Gu, J. Jorne, H. A. Gasteiger, Determination of Catalyst Unique Parameters for the Oxygen Reduction Reaction in a PEMFC, Journal of The Electrochemical Society 153 (10) (2006) A1955-A1963. doi:10.1149/1.2266294.

[67] A. J. Appleby, Oxygen Reduction on Bright Osmium Electrodes in 85\% Orthophosphoric Acid, Journal of The Electrochemical Society 117 (3) (1970) 328-335. doi:10.1149/1.2407759.

[68] S. Jomori, K. Komatsubara, N. Nonoyama, M. Kato, T. Yoshida, An Experimental Study of the Effects of Operational History on Activity Changes in a PEMFC, Journal of the Electrochemical Society 160 (9) (2013) F1067F1073. doi:10.1149/2.103309jes.

[69] T. Morawietz, M. Handl, C. Oldani, K. A. Friedrich, R. Hiesgen, Quantitative in Situ Analysis of Ionomer Structure in Fuel Cell Catalytic Lay- 
ers, ACS Applied Materials and Interfaces 8 (40) (2016) 27044-27054. doi:10.1021/acsami.6b07188.

[70] V. a. Sethuraman, S. Khan, J. S. Jur, A. T. Haug, J. W. Weidner, Measuring oxygen, carbon monoxide and hydrogen sulfide diffusion coefficient and solubility in Nafion membranes, Electrochimica Acta 54 (27) (2009) 6850-6860. doi:10.1016/j.electacta.2009.06.068.

URL http://linkinghub.elsevier.com/retrieve/pii/S0013468609008950

[71] S. Jomori, N. Nonoyama, T. Yoshida, Analysis and modeling of PEMFC degradation: Effect on oxygen transport, Journal of Power Sources 215 (2012) 18-27. doi:10.1016/j.jpowsour.2012.04.069.

[72] H. Xu, R. Kunz, J. M. Fenton, Investigation of Platinum Oxidation in PEM Fuel Cells at Various Relative Humidities, Electrochemical and Solid-State Letters 10 (1) (2007) B1-B5. doi:10.1149/1.2372230.

[73] R. M. Darling, J. P. Meyers, Kinetic Model of Platinum Dissolution in PEMFCs, Journal of The Electrochemical Society 150 (11) (2003) A1523A1527. doi:10.1149/1.1613669.

[74] S. B. Brummer, The Use of Large Anodic Galvanostatic Transients to Evaluate the Maximum Adsorption on Platinum from Formic Acid Solutions, The Journal of Physical Chemistry 69 (2) (1965) 562-571. doi:10.1021/j100886a034.

[75] P. Bastian, M. Blatt, A. Dedner, C. Engwer, R. Klöfkorn, M. Ohlberger, O. Sander, A generic grid interface for parallel and adaptive scientific computing. Part I: abstract framework, Computing 82 (2-3) (2008) 103-119. doi:10.1007/s00607-008-0003-x.

[76] P. Bastian, M. Blatt, A. Dedner, C. Engwer, R. Klöfkorn, R. Kornhuber, M. Ohlberger, O. Sander, A generic grid interface for parallel and adaptive scientific computing. Part II: implementation and tests in DUNE, Computing 82 (2-3) (2008) 121-138. doi:10.1007/s00607-008-0004-9. 
[77] B. Flemisch, M. Darcis, K. Erbertseder, B. Faigle, A. Lauser, K. Mosthaf, P. Nuske, A. Tatomir, M. Wolff, R. Helmig, DuMu ${ }^{\mathrm{X}}$ : DUNE for Multi\{ Phase , Component , Scale , Physics , ... $\}$ Flow and Transport in Porous Media, Advances in Water Resources 34 (9) (2011) 1102-1112. doi:10.1016/j.advwatres.2011.03.007.

[78] P. Bastian, K. Birken, K. Johannsen, S. Lang, N. Neuß, H. Rentz-Reichert, C. Wieners, UG - A flexible software toolbox for solving partial differential equations, Computing and Visualization in Science 1 (1997) 27-40. doi:10.1007/s007910050003.

[79] S. Mthing, P. Bastian, Dune-multidomaingrid: A metagrid approach to subdomain modeling, in: Advances in DUNE, Springer-Verlag Berlin Heidelberg, 2012, pp. 59-73. doi:10.1007/978-3-642-28589-9.

[80] S. Müthing, A Flexible Framework for Multi Physics and Multi Domain PDE Simulations, Ph.D. thesis, University of Stuttgart (2015). doi:10.18419/opus-3620.

[81] R. Huber, R. Helmig, Node-centered finite volume discretizations for the numerical simulation of multiphase flow in heterogeneous porous media, Computational Geosciences 4 (2000) 141-164. doi:https://doi.org/10.1023/A:1011559916309.

[82] W. G. Bessler, Rapid Impedance Modeling via Potential Step and Current Relaxation Simulations, Journal of The Electrochemical Society 154 (11) (2007) B1186-B1191. doi:10.1149/1.2772092.

[83] M. Schulze, E. Gülzow, S. Schönbauer, T. Knöri, R. Reissner, Segmented cells as tool for development of fuel cells and error prevention/prediagnostic in fuel cell stacks, Journal of Power Sources 173 (1) (2007) 19-27. doi:10.1016/j.jpowsour.2007.03.055.

[84] T. Kaz, H. Sander, S. Schönbauer, patent DE10316117 B3 (2004). 
[85] T. Kaz, H. Sander, S. Schönbauer, patent EP1618395 A1 (2007).

[86] M. Schulze, E. Gülzow, K. A. Friedrich, P. Metzger, G. Schiller, Diagnostic Tools for In-situ and Ex-situ Investigations of Fuel Cells and Components at the German Aerospace Center, ECS Transactions 5 (1) (2007) 49-60.

[87] R. Lin, H. Sander, E. Gülzow, A. K. Friedrich, Investigation of Locally Resolved Current Density Distribution of Segmented PEM Fuel Cells to Detect Malfunctions, ECS Transactions 26 (1) (2010) 229-236.

[88] A. El-Kharouf, T. J. Mason, D. J. L. Brett, B. G. Pollet, Exsitu characterisation of gas diffusion layers for proton exchange membrane fuel cells, Journal of Power Sources 218 (2012) 393-404. doi:10.1016/j.jpowsour.2012.06.099.

[89] A. Iranzo, M. Muñoz, F. Rosa, J. Pino, Numerical model for the performance prediction of a PEM fuel cell. Model results and experimental validation, International Journal of Hydrogen Energy 35 (20) (2010) 1153311550. arXiv:arXiv:1011.1669v3, doi:10.1016/j.ijhydene.2010.04.129.

[90] Z. Abdin, C. J. Webb, E. M. A. Gray, PEM fuel cell model and simulation in MatlabSimulink based on physical parameters, Energy 116 (2016) 11311144. doi:10.1016/j.energy.2016.10.033.

[91] P. K. Takalloo, E. S. Nia, M. Ghazikhani, Numerical and experimental investigation on effects of inlet humidity and fuel flow rate and oxidant on the performance on polymer fuel cell, Energy Conversion and Management 114 (2016) 290-302. doi:10.1016/j.enconman.2016.01.075.

URL http://dx.doi.org/10.1016/j.enconman.2016.01.075

[92] L. Hao, K. Moriyama, W. Gu, C.-Y. Wang, Three Dimensional Computations and Experimental Comparisons for a Large-Scale Proton Exchange Membrane Fuel Cell, Journal of The Electrochemical Society 163 (7) (2016) F744-F751. doi:10.1149/2.1461607jes.

URL http://jes.ecsdl.org/lookup/doi/10.1149/2.1461607jes 
[93] G. Hinds, M. Stevens, J. Wilkinson, M. de Podesta, S. Bell, Novel in situ measurements of relative humidity in a polymer electrolyte membrane fuel cell, Journal of Power Sources 186 (1) (2009) 52-57. doi:10.1016/j.jpowsour.2008.09.109.

[94] S. Jeon, J. Lee, G. M. Rios, H. J. Kim, S. Y. Lee, E. Cho, T. H. Lim, J. Hyun Jang, Effect of ionomer content and relative humidity on polymer electrolyte membrane fuel cell (PEMFC) performance of membrane-electrode assemblies (MEAs) prepared by decal transfer method, International Journal of Hydrogen Energy 35 (18) (2010) 9678-9686. doi:10.1016/j.ijhydene.2010.06.044.

URL http://dx.doi.org/10.1016/j.ijhydene.2010.06.044

[95] Q. Yan, H. Toghiani, H. Causey, Steady state and dynamic performance of proton exchange membrane fuel cells (PEMFCs) under various operating conditions and load changes, Journal of Power Sources 161 (1) (2006) 492502. doi:10.1016/j.jpowsour.2006.03.077. 